\title{
Motor Function Deficits in the Estrogen Receptor Beta Knockout Mouse: Role on Excitatory Neurotransmission and Myelination in the Motor Cortex
}

\author{
Mukesh Kumar Varshney ${ }^{a} \quad$ Nancy Yiu-Lin Yu ${ }^{a}$ Shintaro Katayama ${ }^{a} \quad$ Xin Li $^{b}$ \\ Tianyao Liub Wan-Fu Wu ${ }^{c}$ Virpi Töhönen ${ }^{a, d}$ Kaarel Krjutškov ${ }^{a, e, f}$ \\ Juha Kere $^{\mathrm{a}, \mathrm{f}}$ Xiaotang Fan ${ }^{\mathrm{b}}$ José Inzunza ${ }^{a} \quad$ Jan-Åke Gustafsson ${ }^{\mathrm{a}, \mathrm{c}, \mathrm{d}}$ \\ Ivan Nalvarte ${ }^{a}$

\begin{abstract}
${ }^{a}$ Department of Biosciences and Nutrition, Karolinska Institutet, Huddinge, Sweden; ${ }^{b}$ Department of Developmental Neuropsychology, School of Psychology, Third Military Medical University, Chongqing, China; ${ }^{c}$ Center for Nuclear Receptors and Cell Signaling, University of Houston, Houston, TX, USA; ${ }^{d}$ Department of

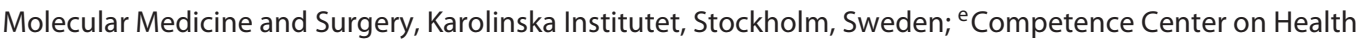
Technologies, Tartu, Estonia; ${ }^{f}$ Folkhälsan Research Institute, Helsinki, and Stem Cells and Metabolism Research Program, University of Helsinki, Helsinki, Finland
\end{abstract}

\section{Keywords}

Estrogen · Estrogen receptor beta · Locomotor activity · Motor cortex $\cdot$ Myelination

\begin{abstract}
Background: Male estrogen receptor beta (ERß) knockout (BERKO) mice display anxiety and aggression linked to, among others, altered serotonergic signaling in the basolateral amygdala and dorsal raphe, impaired cortical radial glia migration, and reduced GABAergic signaling. The effects on primary motor cortex (M1 cortex) and locomotor activity as a consequence of ER $\beta$ loss have not been investigated. Objective: The aim of this study was to determine whether locomotor activity is altered as a consequence of the changes in the M1 cortex. Methods: The locomotor activity of male wild-type (WT) and BERKO mice was evaluated using the open-field and rotarod tests. Molecular changes in the M1 cortex were analyzed by RNA sequencing, elec-
\end{abstract}

tron microscopy, electrophysiology, and immunohistological techniques. In addition, we established oligodendrocyte (OL) cultures from WT and BERKO mouse embryonic stem cells to evaluate $\mathrm{OL}$ function. Results: Locomotor profiling revealed that BERKO mice were more active than WT mice but had impaired motor coordination. Analysis of the M1 cortex pointed out differences in synapse function and myelination. There was a reduction in GABAergic signaling resulting in imbalanced excitatory and inhibitory neurotransmission as well as a defective OL differentiation accompanied by myelin defects. The effects of ER $\beta$ loss on $\mathrm{OL}$ differentiation were confirmed in vitro. Conclusion: $E R \beta$ is an important regulator of GABAergic interneurons and $\mathrm{OL}$ differentiation, which impacts on adult M1 cortex function and may be linked to increased locomotor activity and decreased motor coordination in BERKO mice.

(c) 2020 The Author(s)

Published by S. Karger AG, Basel karger@karger.com www.karger.com/nen

Karger $\stackrel{\text { ' }}{=}$

BOPEN ACCESS (c) 2020 The Author(s)

Published by S. Karger AG, Basel

This article is licensed under the Creative Commons AttributionNonCommercial-NoDerivatives 4.0 International License (CC BYNC-ND) (http://www.karger.com/Services/OpenAccessLicense) Usage and distribution for commercial purposes as well as any distribution of modified material requires written permission.
Ivan Nalvarte

Department of Biosciences and Nutrition Karolinska Institutet, Hälsovägen 7C, Neo

SE-14157 Huddinge (Sweden) ivan.nalvarte@ki.se 


\section{Introduction}

Estrogen signaling in the brain regulates many processes linked to, among others, reproductive behavior [1], neurodegeneration $[2,3]$, and cognition $[2,4]$. The signaling is mediated mainly by two distinct estrogen receptor (ER) subtypes: ER $\alpha$ and ER $\beta$. In adult mice, while ER $\alpha$ is mostly expressed in the periaqueductal gray and hypothalamic preoptic region, where it regulates reproduction, $E R \beta$ is the main ER subtype in the hippocampus, serotonergic neurons of the dorsal raphe, interneurons of the cerebral cortex, and in microglia and oligodendrocytes (OLs) $[1,2,5,6]$. ER $\beta$ knockout (BERKO) mice display increased anxiety-like and context-dependent aggressive behaviors [7-9], vulnerability to neurodegeneration $[10,11]$, and impaired spatial learning [12]. These effects are linked to important neurodevelopmental functions of ER $\beta$. It is the main ER isoform expressed in the brain during early neurodevelopment (both in neurons and glial cells) [13], and lack of ER $\beta$ results in aberrant radial glia migration and cortical layering $[14,15]$ as well as disrupted migration and differentiation of GABAergic interneurons [16]. In addition, ER $\beta$ participates in OL differentiation, proliferation, and migration, which is exemplified by its positive effects on remyelination in models of multiple sclerosis [10, 17].

Our unpublished observations of BERKO mice suggest that these mice are not only more aggressive, but also more motor active. In the present study, behavioral tests confirmed increased locomotor activity and also impaired motor coordination. Gene expression profiling of the BERKO and wild-type (WT) mouse primary motor cortex (M1 cortex), a brain area involved in planning and executing movements, identified two cellular components affected by ER $\beta$ loss: the synapse and the myelin sheath components. Microstructural, electrophysiologi$\mathrm{cal}$, and biochemical analyses revealed that loss of ER $\beta$ results in an imbalance between excitatory and inhibitory GABAergic neurotransmission in the M1 cortex as well as differences in axon myelination, likely through improper OL proliferation and differentiation. This study identified ER $\beta$ as is an important factor in establishing balanced neurotransmission in the M1 cortex to regulate voluntary motor behavior.

\section{Materials and Methods}

Animals and Tissue Isolation

Age-matched and genotyped 16- to 20-week-old C57BL/6 WT or BERKO [18] male mice were housed in a room at standard tem- perature $\left(22 \pm 1^{\circ} \mathrm{C}\right)$ with a regular $12 \mathrm{~h}$ light/12 h dark cycle and given free access to water and standard rodent chow. Mice were anesthetized with sodium pentobarbital ( $50 \mathrm{mg} / \mathrm{kg}$ i.m.) and either transcardially perfused with $1 \times \mathrm{PBS}$, followed by $4 \%$ paraformaldehyde (in $0.1 \mathrm{M}$ PBS, $\mathrm{pH} 7.4$ ) or sacrificed through cervical dislocation (for RNA extraction), and the brain was thereafter dissected out. The left and right M1 cortex was biopsied either by needle puncture (for RNA sequencing) or using a small dissection forceps (approximately $1.0 \times 1.0 \mathrm{~mm}$ pieces for other biochemical analyses) and put individually in tubes containing RNAlater solution (Invitrogen). The tubes were stored at $-80^{\circ} \mathrm{C}$ before RNA extraction.

\section{Behavior Analyses}

Elevated Plus Maze. The maze had two open arms $(68 \mathrm{~cm}$ in length, $5 \mathrm{~cm}$ in width) and two closed arms, which were of the same size but enclosed by $15-\mathrm{cm}$ walls. The maze stood $50 \mathrm{~cm}$ above the ground. The mouse was placed in the center of the maze, facing an open arm, and let to freely explore the maze for $5 \mathrm{~min}$. Time spent in the open and closed arms was recorded with EthoVision XT11 (Noldus, The Netherlands). The maze was thoroughly wiped clean with $20 \%$ ethanol between trials.

Open-Field Test. The animal was placed in the middle of a peripheral zone of an ActiMot2 open-field arena $(50 \times 50 \times 39.5 \mathrm{~cm}$; TSE Systems, Bad Homburg vor der Höhe, Germany) facing the wall and was allowed to freely explore the cage, with the experimenter observing the animal on a video feed in an adjacent room, out of the animal's sight. Each run lasts for $20 \mathrm{~min}$ and was divided into 5-min intervals. The animal's locomotor and rearing activity as well as the time spent in the center $(25 \times 25 \mathrm{~cm}$ square $)$ and periphery (considered everything else than the center square) was recorded using lower and upper $(3 \mathrm{~cm}$ apart) infrared beams dividing the arena into 256 equally sized squares and analyzed using the ActiMot2 software (TSE Systems). Entry into the central or peripheral zone was defined as the movement when the mouse placed all of it paws into the respective zone. The software measured movements throughout the test and averaged the measurements into 5 -min intervals over $20 \mathrm{~min}$. The arena was thoroughly wiped clean with $20 \%$ ethanol between trials.

Rotarod Test. Before the trial, the mice were trained on the rotarod (Ugo Basile rotarod; Stoelting, Wood Dale, IL, USA) for $3 \times$ $3 \mathrm{~min}$ at $20 \mathrm{rpm}$ for three consecutive days to get familiarized with the rotarod. For the next two trial days, the mice were placed on the rotarod using an acceleration paradigm from 10 to $40 \mathrm{rpm}$ over $5 \mathrm{~min}$. In addition, on the third trial day, rotarod speeds were set to 20,30 , and $40 \mathrm{rpm}$ for $5 \mathrm{~min}$. The end of the experiment was considered when the mouse fell off the wheel or until the cutoff time was reached $(5 \mathrm{~min})$. To test motor reference memory, the mice were allowed to run on the rotarod at $40 \mathrm{rpm}$ fixed speed for $5 \mathrm{~min}$, rested for 10 days, and were then again placed on the rotarod at $40 \mathrm{rpm}$ fixed speed for $5 \mathrm{~min}$. Latency to fall and speed was recorded in every test.

All behavioral tests were performed at about 150 lux and during the lights-on period. Consecutive tests were performed on the same time of day. Each animal was allowed to rest for at least $24 \mathrm{~h}$ between behavioral tests, and the order of animals was randomized for each test. Animals were removed from the test based on specific exclusion criteria. These were: (1) in the elevated plus maze: to fall off the maze during experiment; (2) in the open-field test: lack of rearing; (3) in the rotarod test: to run in the direction of the rotarod movement.
Varshney et al. 
Electrophysiology, Spontaneous Excitatory Postsynaptic

Current

Mice were deeply anesthetized with isoflurane and decapitated. Brains were quickly dissected and submerged in ice-cold dissection buffer containing $93 \mathrm{mM} \mathrm{N}$-methyl-D-glucamine, $93 \mathrm{~mm} \mathrm{HCl}$, $2.5 \mathrm{~mm} \mathrm{KCl}, 10 \mathrm{mM} \mathrm{MgSO}_{4}, 1.2 \mathrm{mM} \mathrm{NaH}_{2} \mathrm{PO}_{4}, 30 \mathrm{mM} \mathrm{NaHCO}_{3}$, $25 \mathrm{~mm}$ glucose, $20 \mathrm{mM}$ HEPES, $5 \mathrm{mM} \mathrm{Na}$ ascorbate, $3 \mathrm{~mm} \mathrm{Na}$ pyruvate, $2 \mathrm{mM}$ thiourea, and $0.5 \mathrm{mM} \mathrm{CaCl}_{2}$ and gassed with $95 \%$ $\mathrm{O}_{2} / 5 \% \mathrm{CO}_{2}$ at a rate of $2 \mathrm{~mL} / \mathrm{min}$. Coronal slices $(350 \mu \mathrm{m})$ were obtained using a vibratome (Campden, UK) and transferred into oxygenized artificial cerebrospinal fluid containing $126 \mathrm{mM} \mathrm{NaCl}$, $2.5 \mathrm{mM} \mathrm{KCl}^{2} \mathrm{mM} \mathrm{MgSO}_{4}, 1.25 \mathrm{mM} \mathrm{NaH}_{2} \mathrm{PO}_{4}, 25 \mathrm{mM} \mathrm{NaHCO}_{3}$, $10 \mathrm{mM}$ glucose, and $2 \mathrm{mM} \mathrm{CaCl}_{2}$ to recover at $33^{\circ} \mathrm{C}$ for $30 \mathrm{~min}$ and followed by at least $1 \mathrm{~h}$ of recovery at room temperature before recording.

Slices containing randomly selected (blindly) left or right motor cortex were transferred to the recording chamber, which was perfused continuously with artificial cerebrospinal fluid gassed with $95 \% \mathrm{O}_{2} / 5 \% \mathrm{CO}_{2}$ at a rate of $2 \mathrm{~mL} / \mathrm{min}$. Patch pipettes $(3-$ $6 \mathrm{M} \Omega$ ) were filled with intracellular solution containing $133 \mathrm{mM} \mathrm{K}$ gluconate, $18 \mathrm{~mm} \mathrm{NaCl}$, 0.6 mM EGTA, 2 mM MgATP/Na 3 GTP, and $10 \mathrm{mM}$ HEPES. To record spontaneous excitatory postsynaptic currents, neurons were voltage-clamped at $-70 \mathrm{mV}$ in the presence of picrotoxin $(50 \mu \mathrm{M})$. Electrical signals were filtered at $2 \mathrm{kHz}$ and digitized at $10 \mathrm{kHz}$ using Multiclamp 700B (Molecular Devices, USA) and Digidata 1550B (Molecular Devices). Data were analyzed offline using the MiniAnalysis software (Synaptosoft Inc., USA).

\section{RNA Isolation, cDNA Synthesis, and Quantitative Real-Time} qPCR Analysis

For RNA sequencing and RT-qPCR analysis, total RNA was isolated using the RNeasy Plus Micro kit and the RNeasy kit, respectively (both from Qiagen, Hilden, Germany) according to the manufacturer's recommendations. RNA from left and right motor cortex was used. cDNA was synthesized using the Superscript Vilo master mix kit containing random hexamers (Thermo Fischer Scientific, Waltham, MA, USA). RT-qPCR measurements were performed using $0.5 \mu \mathrm{L} \mathrm{cDNA}, 300 \mathrm{nM}$ forward and reverse primers (online suppl. Table I; for all online suppl. material, see www. karger.com/doi/10.1159/000506162) and SYBR green PCR master mix according to the manufacturer's instructions (Applied Biosystems, Foster City, CA, USA). The RT-qPCRs were set up and run on a 7500 fast real-time system (Applied Biosystems) and relative mRNA expression was analyzed using the $\Delta \Delta \mathrm{Ct}$ method normalized to $18 \mathrm{~S}$ rRNA or Rplp0 and to WT control sample. Amplification efficiencies were calculated at the geometric phase of the PCR amplification using the 7500 Software v2.0.6 (Applied Biosystems). Only amplification efficiencies of $100 \%$ were included in the analyses.

\section{RNA Sequencing Using the Single-Cell Tagged Reverse \\ Transcription Protocol}

Depending on the RNA concentration of the sample, the quality was measured by RNA 6000 Pico $(<15 \mathrm{ng} / \mu \mathrm{L})$ or Nano assay $(>15 \mathrm{ng} / \mu \mathrm{L}$ ) (Agilent 2100 Bioanalyzer; Agilent, Santa Clara, CA, USA) by calculation of RNA integrity number values. RNA samples with RNA integrity number values around 8 or above were chosen for sequencing. Ten nanograms of RNA from left and right $\mathrm{M} 1$ cortex biopsies from $6 \mathrm{WT}$ and $6 \mathrm{BERKO}$ mice were processed using the single-cell tagged reverse transcription (STRT) RNA sequencing protocol [19]. Although the protocol used was originally described for fluorescence-activated cell sorting single-cell analysis [20], it can be used for RNA sequencing of low amounts of cells isolated in other ways, such as by needle puncture in the present study. Briefly, RNA samples were placed in a 48-well plate in which a universal primer, template-switching helper oligos with a wellspecific 6-bp barcode sequence (for sample identification), and a 6-bp random sequence for unique molecular identifier [21] were added to each well. Reverse transcription reagents and ERCC RNA Spike-In Mix I (both from Thermo Fischer Scientific) were added to generate first-strand cDNA. The synthesized cDNAs from the samples were then pooled into one library and amplified by singleprimer PCR with the universal primer sequence. The resulting amplified library was then sequenced in three lanes using the Illumina HiSeq 2000 instrument (Illumina, San Diego, CA, USA).

\section{Gene Expression Analysis of Sequenced RNA}

Data processing of the sequenced RNA libraries was performed using the STRTprep version v3dev pipeline (https://github.com/ shka/STRTprep) as described in Krjutškov et al. [20]. Briefly, the reads were de-multiplexed into individual samples using the sample-specific barcodes, and redundancies in the reads, mainly due to PCR amplification, were reduced according to unique molecular identifiers [21]. The processed reads were mapped to the mouse genome assembly MGSCv37 (mm9) with RefSeq annotations [22] using Bowtie1 [23] and assembled into transcript regions using TopHat v.2.0.12 [24]. For quality control, samples with low read counts $(<200,000$ reads/sample), high redundancy $(>10)$, shallow spike-in counts $(<700$ reads/sample), low spike-in map rate $(<90 \%)$, and low map rate to $5^{\prime}$-end of genes $(<70 \%)$ were excluded from subsequent analyses. Variation caused by technical noise was estimated from technical replicates using a generalized linear model with a gamma distribution, as described in Krjutškov et al. [20]. As technical variations were determined to be smaller than biological ones, read counts from technical replicates of each sample were combined by summation to produce a single transcription start site profile for each biological sample. Normalization of gene expression values was calculated as read counts relative to total spike-in counts for each sample (in total six samples from each mouse: left and right motor cortex run in technical triplicates). The sample from one BERKO mouse was removed from the final analysis as its transcription profiles were outliers compared to the other BERKO mouse cortex profiles. Differential expression analysis was performed using SAMstrt [25], which uses Poisson resampling and nonparametric statistics based on SAMseq to determine differentially expressed genes [26]. SAMseq estimated false discovery rates based on the permutation plug-in method [26, 27]. The data are accessible through Gene Expression Omnibus series accession number GSE139428 (www.ncbi.nlm.nih.gov/geo/ query/acc.cgi?acc=GSE139428).

\section{Tissue Preparation and Immunohistochemistry}

Immunohistochemical localization of antigens of interest was performed on perfusion-fixed brains. Following fixation, brains were removed and whole brain was slid into the cavity of a brain matrix (coronal $3 \mathrm{~mm}$; Stoelting Inc., Dublin, Ireland) and cut into 3 -mm equal coronal slices. These slices were then post-fixed in the same fixative at $4{ }^{\circ} \mathrm{C}$ overnight followed by PBS wash for $2-3 \mathrm{~h}$. Brain slices were either paraffin-embedded or processed for cryo- 
sectioning by cryoprotection immersing first in 15\% (24 h) and then in $30 \%$ (overnight) sucrose solution (in $0.1 \mathrm{M}$ phosphate buffer, $\mathrm{pH}$ 7.4) at $4{ }^{\circ} \mathrm{C}$ until the tissue sank to the bottom. The desired coronal slice of the brain (bregma ca. 0.5 [lateral -0.72 to $1.32 \mathrm{~mm}]$ ) was oriented in the sectioning plane in a cryomold with OCT compound (Thermo Fischer Scientific), snap-frozen, and stored at $-80^{\circ} \mathrm{C}$ until use. Coronal sections of $10 \mu \mathrm{m}$ thickness were cut and collected on SuperFrost Plus slides (Thermo Fischer Scientific) for cytoarchitectural studies, while $30-\mu \mathrm{m}$-thick sections were cut and collected in PBS, pH 7.4 for immunohistochemical studies. To achieve uniformity of results, care was taken to process the tissue sections from various experimental and control groups simultaneously.

Thirty-micrometer-thick cryosections (or 5- $\mu$ m-thick paraffin sections processed as described in Tan et al. [28]) were used for immunostaining. In brief, tissue sections were rinsed in PBS and processed free floating throughout the procedure. All steps were performed at room temperature, except for primary antibody incubation at $4{ }^{\circ} \mathrm{C}$. Sections were incubated with $1 \%$ sodium borohydride (Sigma Aldrich) in PBS followed by rinsing with wash buffer $(0.01 \%$ Tween 20 in PBS). Sections were permeabilized by incubating with $2 \%$ Triton X-100 diluted in PBS followed by incubation in blocking buffer (3\% BSA, $0.1 \%$ Tween 20 in PBS). Wherever mouse antibodies were used, the tissue sections were incubated with goat anti-mouse IgG (1:10, Abcam) for endogenous mouse IgG blocking. Further, tissue sections were incubated with primary antibodies for $24-48 \mathrm{~h}$ at $4{ }^{\circ} \mathrm{C}$ followed by several washes with wash buffer and incubation with secondary antibodies (Alexa Fluor 488, Alexa Fluor 568, 1:1,000 in PBS, Thermo Fischer Scientific, or donkey anti-chicken FITC, donkey anti-mouse Cy3, donkey anti-rabbit Cy3 1:400, Jackson Immuno Research). Sections were washed several times in wash buffer, rinsed in distilled water, and incubated in $1 \mathrm{mM} \mathrm{CuSO}_{4}$ (in $50 \mathrm{mM}$ ammonium acetate, $\mathrm{pH}$ 5.0) followed by rinsing in water and wash buffer. Immunostained sections were further incubated with DAPI $(300 \mathrm{nM}$, Molecular Probes), followed by rinsing in wash buffer and coverslip mounting using Permafluor hardset mounting medium (Thermo Fischer Scientific) and stored at $4{ }^{\circ} \mathrm{C}$ in the dark. Immunostaining of the cultured cells on coverslips was performed similarly, with the exception that no sodium borohydride, Triton X-100, or $1 \mathrm{~mm}$ $\mathrm{CuSO}_{4}$ was used.

The primary antibodies were chicken anti-ER $\beta$ (1:100, developed in-house), mouse anti-ER $\beta$ (1:500, 14C8, Genetex), rabbit anti-NeuN (1:250, ab104225, Abcam), rabbit anti-MBP (1:200, \#78896, Cell Signaling Technology), rabbit anti-PLP (1:1,000, \#PA3-151, Thermo Fischer Scientific), goat anti-Olig2 (1:50, \#AF2418, R\&D Systems, Minneapolis, MN, USA), and goat anticalretinin (1:2,000, \#AB1550, Millipore).

Immunofluorescent images were captured using an AxioPlan2 fluorescent microscope (Carl Zeiss, Oberkochen, Germany) and the Zeiss AxioVision 4.0 software (Carl Zeiss), or using the Zeiss LSM710-NLO single-point scanning confocal microscope (Carl Zeiss) and the Zeiss Zen software (Carl Zeiss). Single scans, stitched overview images, and maximum intensity projections were analyzed with the Fiji image analysis software (Image); National Institutes of Health, Bethesda, MD, USA).

\section{Nissl Staining}

Ten-micrometer-thick cryosections on SuperFrost Plus slides were used for Nissl staining for cytoarchitectural studies. Briefly, the sections were brought to room temperature and rinsed with deionized distilled water followed by incubation in $0.1 \%$ cresyl violet at $60^{\circ} \mathrm{C}$. Stained sections were rinsed with distilled water and dehydrated through ascending grades of ethanol (50 and 70\%) followed by rinsing in differentiation solution (95\% ethanol $+0.1 \%$ acetic acid) and few dips in $100 \%$ ethanol. Sections were placed in xylene and mounted with DPX, a xylene-based mounting medium, and glass coverslips. The sections were imaged as above.

\section{Transmission Electron Microscopy}

For electron microscopy, the anesthetized mice were transcardially perfused with fixative $(2.5 \%$ glutaraldehyde, $1 \%$ paraformaldehyde in $0.1 \mathrm{M}$ phosphate buffer, $\mathrm{pH}$ 7.4). The brain was dissected and the desired pieces were cut and stored in the same fixative at $4^{\circ} \mathrm{C}$ overnight. Samples were washed in $0.1 \mathrm{M}$ phosphate buffer, post-fixed in $2 \% \mathrm{OsO}_{4}$ in $0.1 \mathrm{M}$ phosphate buffer for $2 \mathrm{~h}$ at $4{ }^{\circ} \mathrm{C}$, dehydrated in ethanol followed by acetone, and embedded in LX112 (Ladd, Burlington, VT, USA). Ultrathin sections (50-60 nm) were cut using Leica EM UC 6 (Leica, Vienna, Austria) and contrasted with uranyl acetate followed by lead citrate. The sections were examined in a Tecnai 12 Spirit Bio TWIN transmission electron microscope (FEI Company, Eindhoven, The Netherlands) at $100 \mathrm{kV}$ and images were acquired using a Veleta camera (Olympus, Münster, Germany). Randomly selected images from the M1 cortex or frontal cortex layers I-III were used to quantify presynaptic vesicles, number of synapses, presynaptic mitochondria, and myelin thickness. The quantifications were performed with Fiji image analysis software (ImageJ).

\section{Brain-Derived Neurotrophic Factor Measurement}

WT and BERKO cortical pieces (ca. $1 \mathrm{~mm}^{3}$ in size, left and right cortex combined) were homogenized in lysis buffer (50 mM Tris$\mathrm{HCl} \mathrm{pH} \mathrm{8.0,} 150 \mathrm{~mm} \mathrm{NaCl}, 5 \mathrm{~mm}$ EDTA, 0.5\% [v/v] Nonidet P-40, $0.5 \%[\mathrm{v} / \mathrm{v}]$ Triton X-100, 0.1\% sodium deoxycholate, $1 \mathrm{mM}$ dithiotreitol, and protease inhibitors [all from Sigma Aldrich]) using a bounce glass-glass homogenizer. Lysates were centrifuged at $24,000 \mathrm{~g}, 40 \mathrm{~min}$, at $4{ }^{\circ} \mathrm{C}$. Brain-derived neurotrophic factor (BDNF) levels in supernatants were measured using the Mouse BDNF ELISA kit from Abnova according to the manufacturer's instructions (Abnova, Taipei, Taiwan).

\section{Generation of OLs from Mouse Embryonic Stem Cells}

OL precursor cells (OPCs) and OLs were derived from mouse embryonic stem cells (mESCs) of WT and BERKO mice. mESCs utilized in this study have been derived and characterized previously and were cultured as described earlier [29]. The feeder-independent mESCs were subsequently used for OPC derivation. All cultures were maintained in a humidified incubator at $37^{\circ} \mathrm{C}$ and $5 \% \mathrm{CO}_{2}$. Embryoid bodies (EBs) were generated by plating mESCs at a density of $5.5 \times 10^{5}$ cells $/ \mathrm{mL}$ in ES medium (without LIF and two inhibitors) in a $100-\mathrm{mm}$ non-tissue culture-treated dish. On day 4, EBs were plated on gelatin-coated $100-\mathrm{mm}$ tissue culture dishes in EB medium supplemented with $10 \%$ ES qualified FBS. EBs were allowed to attach to the surface overnight at $37^{\circ} \mathrm{C}, 5 \%$ $\mathrm{CO}_{2}$. On the next day, the EB medium was replaced with neural stem cell derivation medium containing $387 \mathrm{mg} / \mathrm{L}$ glucose, $18 \mathrm{mg} / \mathrm{L}$ L-glutamine, $1 \times$ ITS medium supplement (R\&D Systems) in knockout DMEM/F12 without glutamine, and HEPES (Thermo Fischer Scientific). Recombinant bovine fibronectin (R\&D Systems) was added to this medium at a final concentration of $5 \mu \mathrm{g} /$
30

Neuroendocrinology 2021;111:27-44 DOI: $10.1159 / 000506162$
Varshney et al. 
$\mathrm{mL}$ just prior to use. Cells were cultured for $6-8$ days at $37^{\circ} \mathrm{C}, 5 \%$ $\mathrm{CO}_{2}$. The medium was changed every other day. During this period, a monolayer of neural progenitor cells with rosette-like morphology grew from the attached EBs. Subsequently, cells were dissociated with Accutase (Thermo Fisher Scientific) and collected in a $15-\mathrm{mL}$ tube containing stem cell derivation medium. Cell clumps (remnants of EB) were removed by keeping the tube to stand until the cell clumps settled to the bottom. Suspended neural progenitor cells were collected and spun at 1,200 rpm for $5 \mathrm{~min}$ and plated on poly-L-ornithine- $(50 \mu \mathrm{g} / \mathrm{mL}$; Sigma Aldrich $)$ and laminin- $(1 \mu \mathrm{g} /$ $\mathrm{mL}$; Novus Biologicals, Littleton, CO, USA) coated dishes at a seeding density of $5 \times 10^{4}$ cells $/ \mathrm{cm}^{2}$. Cells were cultured in neural expansion medium (NSE, $1.5 \mathrm{mg} / \mathrm{mL}$ glucose, $73 \mu \mathrm{g} / \mathrm{mL}$ L-glutamine, $1 \times \mathrm{N} 2$ medium supplement (R\&D Systems) or $1 \times$ Neuro- 2 supplement (EMD Millipore, Solna, Sweden) in knockout DMEM/ F12 (without glutamine and HEPES; Invitrogen) supplemented with $10 \mathrm{ng} / \mathrm{mL}$ fibroblast growth factor basic (Peprotech, Rocky Hill, NJ, USA) and $1 \mu \mathrm{g} / \mathrm{mL}$ laminin (Novus Biologicals) for 4 days. Subsequently, the NSE medium was additionally supplemented with $10 \mathrm{ng} / \mathrm{mL}$ epidermal growth factor (Peprotech) for the next 4 days followed by NSE medium supplemented with $10 \mathrm{ng} / \mathrm{mL}$ fibroblast growth factor basic and $20 \mathrm{ng} / \mathrm{mL}$ platelet-derived growth factor AA (Peprotech) for another 4 days. Confluent cells obtained after the procedure were confirmed for oligodendroglial lineage (OPCs) with Olig2 or A2B5 (R\&D Systems) staining. These OPCs were dissociated using Accutase and were further expanded in NSE medium supplemented with $10 \mathrm{ng} / \mathrm{mL}$ fibroblast growth factor basic and $20 \mathrm{ng} / \mathrm{mL}$ platelet-derived growth factor AA or cryopreserved in liquid nitrogen. For terminal differentiation and maturation of OPCs, cells were cultured in NSE medium supplemented with $30 \mathrm{ng} / \mathrm{mL} \mathrm{T3}\left(3,3^{\prime}, 5\right.$-triiodo-L-thyronine, sodium salt; Sigma Aldrich) for 6-8 days with medium change every 2 days. After this period, OLs were identified by staining with O4, PLP1, or CNPase antibodies.

Image Analysis

Quantification of absolute cell count of calretinin-positive interneurons in the M1 cortex was performed using a Fiji image analysis program (ImageJ). Coronal brain sections around bregma 0.5 were immunostained for calretinin, and low-magnification $(5 \times$ objective) images were captured for counting. Every fourth section was used for this purpose, and 4-5 sections per mouse were used. Each group included five age-matched mice, and the counts from each section were averaged. Images were first converted to 8-bit grayscale and subjected to background correction by subtracting an unstained area (corpus callosum) following the protocol described by Mehra et al. [30]. An optimal threshold was selected for each image to exclude bias resulting from different image threshold values in different images. A region of interest of $1 \mathrm{~mm}^{2}$ was drawn and overlaid on each image at the same cortical area. Resulting images were scanned for positive spots which were set to be between $7 \times 7$ and $12 \times 12$ pixels in size and were counted automatically by setting up the analyze particles command in the Fiji software.

Similarly, Mbp staining in layers II-III of the M1 cortex was analyzed in the Fiji image analysis program by quantifying mean gray intensity (in arbitrary units) of the staining relative to an unstained background image.

Quantification of mature OL process length and process count was performed on immunofluorescent images from cells grown on glass coverslips and immunostained for PLP1 (OL-specific marker) and DAPI. Four to five images from nonoverlapping regions from each coverslip were taken for analysis, and each group consisted at least three coverslips. Images were first converted to 8-bit grayscale and subjected to background correction as described in Mehra et al. [30], followed by applying median filter, optimal threshold selection (as described above), and sharpening in the Fiji software. The NeurphologyJ plugin [31], with some modifications (see online suppl. methods), was applied to the images for automated counting of processes and overall length measurement. In all image analyses, images were also scrutinized manually by another person unknown to the procedure. Image analysis and quantifications were performed using the same settings for each marker across all stages as well as across all populations.

\section{Statistical Analyses}

The experiments represent data from at least three independent biological replicates. Unless stated otherwise, the statistical differences between groups were analyzed using the GraphPad Prism 6 software (GraphPad Software Inc., San Diego, CA, USA) by ordinary one- or two-way ANOVA, followed by Dunnett's, Bonferroni's, or Tukey's post hoc test for multiple comparisons, by unpaired Student's $t$ test for single comparisons, or by linear regression for scatter plots. $p$ values $<0.05$ were considered statistically significant. Data are expressed as means \pm standard deviations or standard error of the mean as stated in the figure legends.

\section{Results}

\section{Loss of ER $\beta$ Affects Locomotor Activity and Motor Coordination}

In the elevated plus maze, BERKO mice made fewer entries (Fig. 1a) and spent less time (Fig. 1b) in the open arms of the maze compared to age-matched adult (ca. 20-week-old) WT littermates, which is in line with previous reports describing increased anxiety behavior in BERKO mice [7, 12, 32]. In the open-field test which measures locomotor activity, WT and BERKO mice were allowed to freely explore the open-field arena. Mice of both genotypes spent equal time in the center area of the arena (Fig. 1c). However, BERKO mice were more locomotor active with greater distance traveled (Fig. 1d) and at a higher velocity (Fig. 1e), with an overall significant main effect of genotype. In addition, an overall effect of genotype was found in rearing frequency, where BERKO mice displayed higher rearing activity compared to WT mice, with the greatest differences between 5 and 15 min into the open-field test (Fig. 1f). To evaluate motor coordination and motor reference memory, the rotarod test was used. The mice were trained for three consecutive days on the rotarod three times at $10 \mathrm{rpm}$ for $3 \mathrm{~min}$ and thereafter subjected to accelerating speed $(10-40 \mathrm{rpm})$ during the next two consecutive days. BERKO mice had a signifi- 
cantly lower latency to fall on both trial days compared to WT mice (Fig. 1g). Although both WT and BERKO mice appeared to improve performance on the second trial day (not significantly), BERKO mice still performed worse than WT mice (Fig. 1g). At 20, 30, and $40 \mathrm{rpm}$ fixed speed the BERKO mice again showed a significantly lower latency to fall compared to WT mice (Fig. 1h). Performance did not improve after 10 days of rest (Fig. 1i). These data demonstrate that mice lacking $\operatorname{ER} \beta$ are more locomotor active, but perform worse in the rotarod motor coordination and motor reference memory tests.
Gene Profiling Analysis of BERKO Motor Cortex

We next performed RNA sequencing (using the STRT RNA sequencing protocol) of WT and BERKO M1 cortex, a brain area that supports planning and execution of movements as well as motor skill learning. Left and right M1 cortices from $6 \mathrm{WT}$ and 6 BERKO mice were biopsied at bregma ca. 0.5 , penetrating layers ca. I-IV (Fig. 2a), and analyzed by RNA sequencing. After sequencing quality control processing, differential gene expression analysis of $6 \mathrm{WT}$ and 5 BERKO mouse cortices (left and right) was performed, resulting in a list

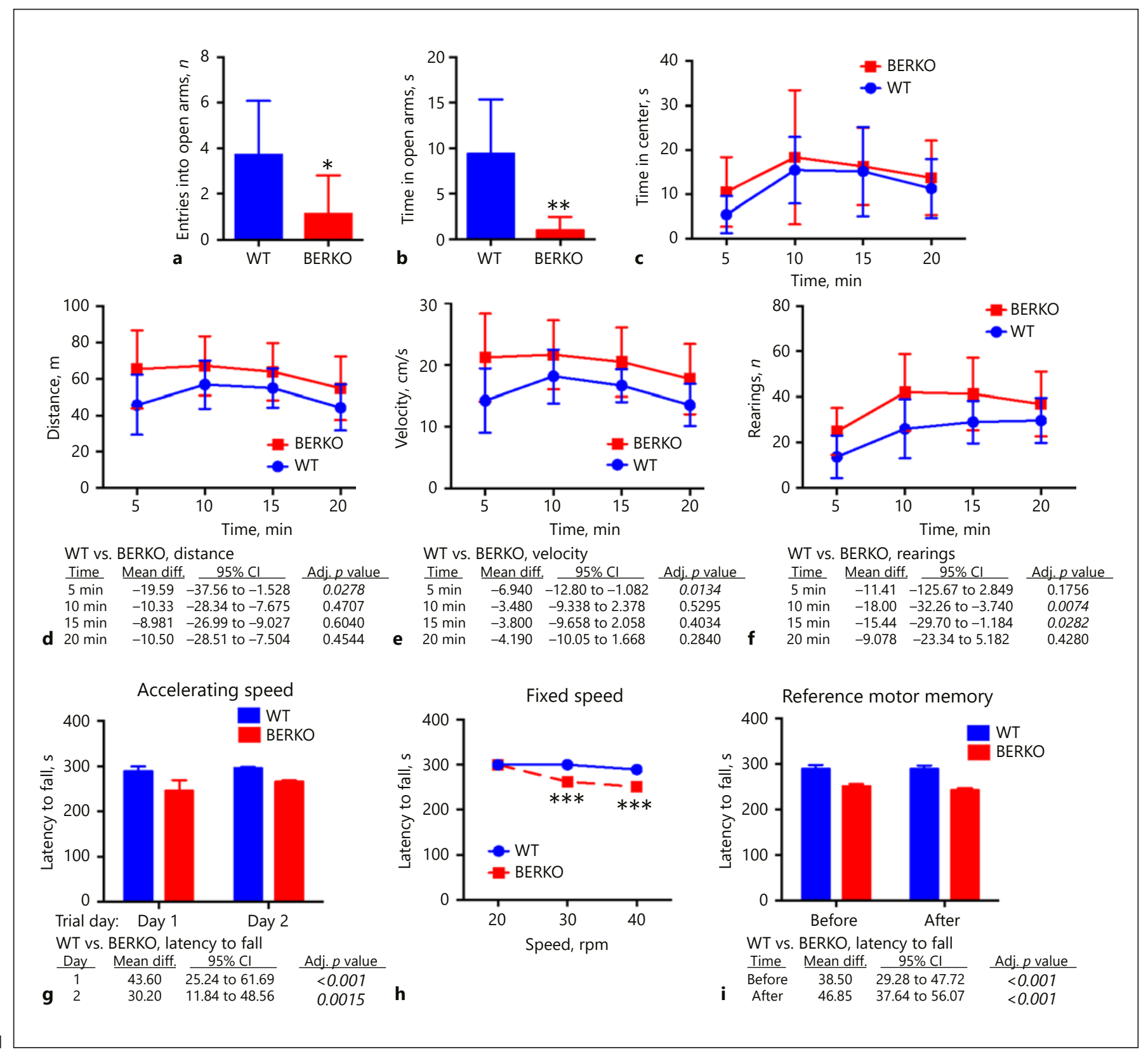

(For legend see next page.) 
of 126 differently regulated transcripts (Fig. 2b; online suppl. data file 1 ).

The pathway analysis of downregulated transcripts gave no significant hits, whereas upregulated transcripts were involved in the myelin sheath component (Table 1). When all differently regulated transcripts were combined, there were significant differences in pathways involved in synapse and myelin sheath components as well as in dendrite extension processes (Table 1).

Surprisingly, we also detected differences in gene expression between the biopsies taken from the left and right M1 cortex (online suppl. Fig. 1A; online suppl. Ta- ble II) and that only a few differently regulated genes were commonly regulated between left and right biopsies (online suppl. Fig. 1B). To confirm these differences, we isolated whole left and right M1 cortices using a dissection forceps and performed RT-qPCR analysis on a selection of the identified genes that were grouped to specific pathways (Table 1). Except for the gene Arc, we could not detect any significant differences between left and right M1 cortices for individual genes (online suppl. Fig. 1C-E) by RT-qPCR. However, a slight general increase in gene expression was observed in the right compared to left BERKO M1 cortex (online suppl. Fig. 1D, E), but effects

Table 1. g:Profiler pathway analysis of up- and/or downregulated transcripts in BERKO M1 cortex compared to WT

\begin{tabular}{lllll}
\hline & Enriched pathway & Type & $\begin{array}{c}-\log 10 \\
p \text { value }\end{array}$ & Gene names \\
\hline Up & myelin sheath & cellular component & 2.57 & Cox5a, Cnp, Cntnap1, Plp1, Cldn11, Mbp, Gapdh, Actg1 \\
\hline Down & N/A & N/A & & \\
\hline Up or down & synapse & cellular component & 1.43 & $\begin{array}{l}\text { Mef2c, Atp2b1, Scamp1, Arc, Dclk1, Dnajc6, Rims2, Kcnj10, } \\
\text { Chrm2, Kcna1, Syngr2, Nrgn, Synpr, Syt17, Nrxn3 }\end{array}$ \\
\cline { 2 - 5 } & myelin sheath & cellular component & 1.50 & Cox5a, Cnp, Cntnap1, Plp1, Cldn11, Mbp, Gapdh, Actg1 \\
\cline { 2 - 5 } & dendrite extension & biological process & 1.72 & Cpne6, Cpne9, Rims2, Syt17 \\
\hline
\end{tabular}

Pathways were considered significantly enriched if $-\log 10 p>1.30$. BERKO, estrogen receptor beta knockout; M1 cortex, primary motor cortex; N/A, not applicable; WT, wild-type.

Fig. 1. BERKO mice are more locomotor active but less motor coordinated. a, b Anxiety test using an elevated plus maze show that BERKO mice made less number of entries ( $t$ test $t=2.350, \mathrm{df}=12$, $p=0.0367)$ in the open arms (a) and spent less time ( $t$ test $t=3.630$, $\mathrm{df}=12, p=0.0034)$ in the open arms of the maze (b). c Open-field locomotor test measuring the cumulative time (in 5-min intervals over $20 \mathrm{~min}$ ) that WT and BERKO mice spent in the center part of the arena (two-way ANOVA of the main effect of genotype $F_{(1,18)}=1.1555, p=0.2966$; time interval $F_{(3,54)}=5.126, p=0.0034$; and interaction between genotype and time interval $F_{(3,54)}=0.2229$, $p=0.8801$ ). $\mathbf{d}$ The cumulative distance covered (in $\mathrm{m}$ ) during 5 -min time intervals over $20 \mathrm{~min}$ (two-way ANOVA of the main effect of genotype $F_{(1,18)}=4.832, p=0.0413$; time $F_{(3,54)}=4.788$, $p=0.0050$; and interaction between genotype and time $F_{(3,54)}=$ $0.9828, p=0.4078$ ). e Average velocity during 5 -min time intervals over $20 \mathrm{~min}$ (two-way ANOVA of the main effect of genotype $F_{(1,18)}=7.161, p=0.0154$; time $F_{(3,54)}=4.222, p=0.0094$; and interaction between genotype and time $F_{(3,54)}=0.8304, p=0.4830$ ). f Cumulative number of rearings during 5 -min time intervals over 20 min (two-way ANOVA of the main effect of genotype $F_{(1,17)}=$ 9.543, $p=0.0067$; time $F_{(3,51)}=16.32, p<0.001$; and interaction between genotype and time $\left.F_{(3,51)}=1.013, p=0.3947\right)$ in the openfield test. $\mathbf{g}$ Rotarod motor coordination test measuring latency to fall on trial days 1 and 2 at accelerating speed (10-40 rpm) during 5-min trial. Two-way ANOVA showed that there was a significant difference in genotype in latency to fall (main effect of genotype $F_{(1,20)}=47.41, p<0.001$; trial day $F_{(1,20)}=6.441, p=0.0196$; and interaction between genotype and trial day $F_{(1,20)}=1.563, p=$ $0.2256)$. $\mathbf{h}$ Latency to fall at 20,30 , and $40 \mathrm{rpm}$ rotarod fixed speed during 5-min trial (main effect of genotype $F_{(1,24)}=270,5, p<$ 0.001 ; speed $F_{(1,24)}=127.4, p<0.001$; and interaction between genotype and speed $\left.F_{(1,24)}=67.68 p<0.001\right)$. i Motor reference memory test at $40 \mathrm{rpm}$ fixed rotarod speed over $5 \mathrm{~min}$ before and after a 10-day resting period (main effect of genotype $F_{(1,20)}=251.8, p<$ 0.001 ; before or after rest $F_{(1,20)}=2.708, p=0.1155$; and interaction between genotype and before or after rest $F_{(1,20)}=2.410, p=$ $0.1362)$. $p$ values to detect significant effects between genotypes in $\mathbf{a}$ and $\mathbf{b}$ were obtained using Student's $t$ test and in $\mathbf{d - i}$ using regular two-way ANOVA with Bonferroni's correction for multiple comparisons. Differences detected in the absence of interaction are highlighted in the statistical boxes below the graphs and indicate mean differences of factor, $95 \% \mathrm{CI}$, and adjusted $p$ value. ${ }^{*} p<0.05$, ${ }^{* *} p<0.01,{ }^{* * *} p<0.001$ compared to WT at the respective timepoint or condition. Data represent means \pm standard deviations ( $n=7$ in $\mathbf{a}$ and $\mathbf{b}, n=9-10$ in $\mathbf{c}-\mathbf{f}, n=6$ in $\mathbf{g}$ and $\mathbf{I}$, and $n=5$ in $\mathbf{h}$ for each genotype). BERKO, estrogen receptor beta knockout; CI, confidence interval; WT, wild-type. 


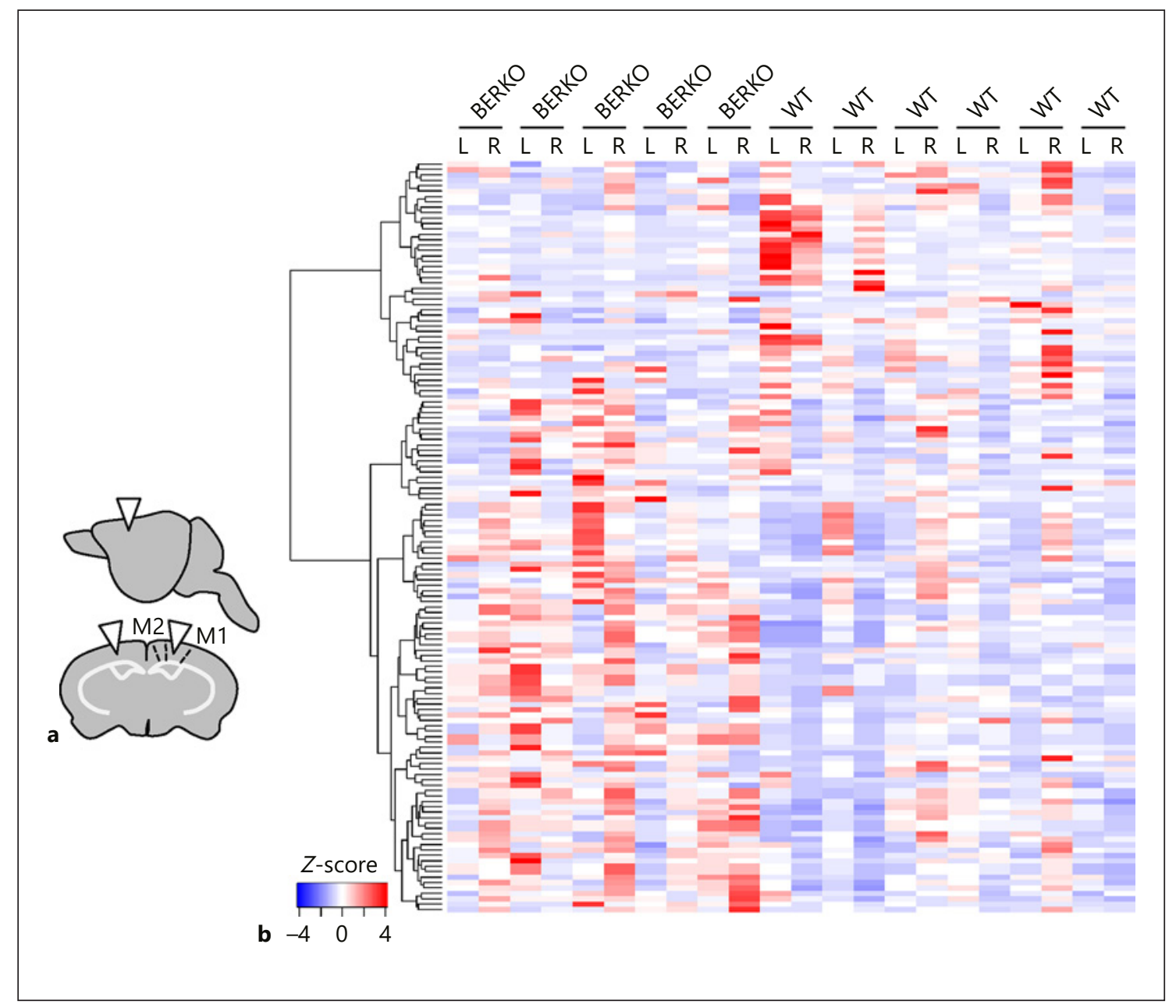

Fig. 2. RNA sequencing analysis of WT and BERKO M1 cortex. a Illustration of excised M1 cortex area (at bregma ca. 0.5 [lateral -0.72 to $1.32 \mathrm{~mm}$ ], arrowheads) used for STRT RNA sequencing. $\mathbf{b}$ Heatmap of differently expressed genes between WT and BERKO left (L) and right (R) M1 cortices. Levels are based on log2 mean signal intensities, red and blue denote high and low expression levels, respectively (BERKO $n=5$, WT $n=6$ ). BERKO, estrogen receptor beta knockout; M1 cortex, primary motor cortex; M2 cortex, secondary motor cortex; STRT, single-cell tagged reverse transcription; WT, wild-type.

Fig. 3. Loss of ER $\beta$ affects M1 cortex synapses. a, b RT-qPCR analysis of differently regulated genes involved in dendrite extension process (a) and the synapse component (b) in right BERKO compared to right WT M1 cortex (dashed line). The data represent expression values from right M1 cortex (online suppl. Fig. 1C, D). c Representative TEM images of WT and BERKO M1 cortex (layers III-V). Synapses are visible as electron-dense dark structures (white arrowheads). Scale bars, $2 \mu \mathrm{m}$. d Quantification of synapses per $\mu \mathrm{m}^{2}$ ( $t$ test $\left.t=3.062, \mathrm{df}=10, p=0.0120\right)$. e Magnified images showing excitatory asymmetric (black arrowheads) and inhibitory symmetric (yellow arrowhead) synapses. Scale bars, $500 \mathrm{~nm}$. f Quantification of presynaptic neurotransmitter vesicles (exemplified by blue arrowheads in e) in excitatory presynapses ( $t$ test $t=7.724, \mathrm{df}=10, p<0.001)$. g Quantification of postsynaptic den- sity in WT and BERKO M1 cortex by calculating gray intensity ( $t$ test $t=1.363, \mathrm{df}=10, p=0.2027)$. $\mathbf{h}$ Number of inhibitory symmetric GABAergic synapses per $\mu \mathrm{m}^{2}$ (exemplified by yellow arrowhead in e) ( $t$ test $t=5.429, \mathrm{df}=8, p<0.001)$. i Quantification of neurotransmitter vesicles in these inhibitory synapses of WT and BERKO M1 cortex ( $t$ test $t=0.5525, \mathrm{df}=10, p=0.5928$ ). $p$ values were obtained using one-way ANOVA with Dunnett's correction for multiple comparisons $(\mathbf{a}, \mathbf{b})$ or ordinary Student's $t$ test $(\mathbf{d}, \mathbf{f}-\mathbf{i}) .{ }^{*} p<0.05,{ }^{* *} p<0.01,{ }^{* * *} p<0.001$ compared to WT. Data represent means \pm standard errors of the mean $(n=5$ in $\mathbf{a}, \mathbf{b}$, $\mathbf{h} ; n=6$ in $\mathbf{d}, \mathbf{f}, \mathbf{g}, \mathbf{i})$. AU, arbitrary units; BERKO, estrogen receptor beta knockout; ER $\beta$, estrogen receptor beta; M1 cortex, primary motor cortex; TEM, transmission electron microscopy; WT, wild-type.

(For figure see next page.) 

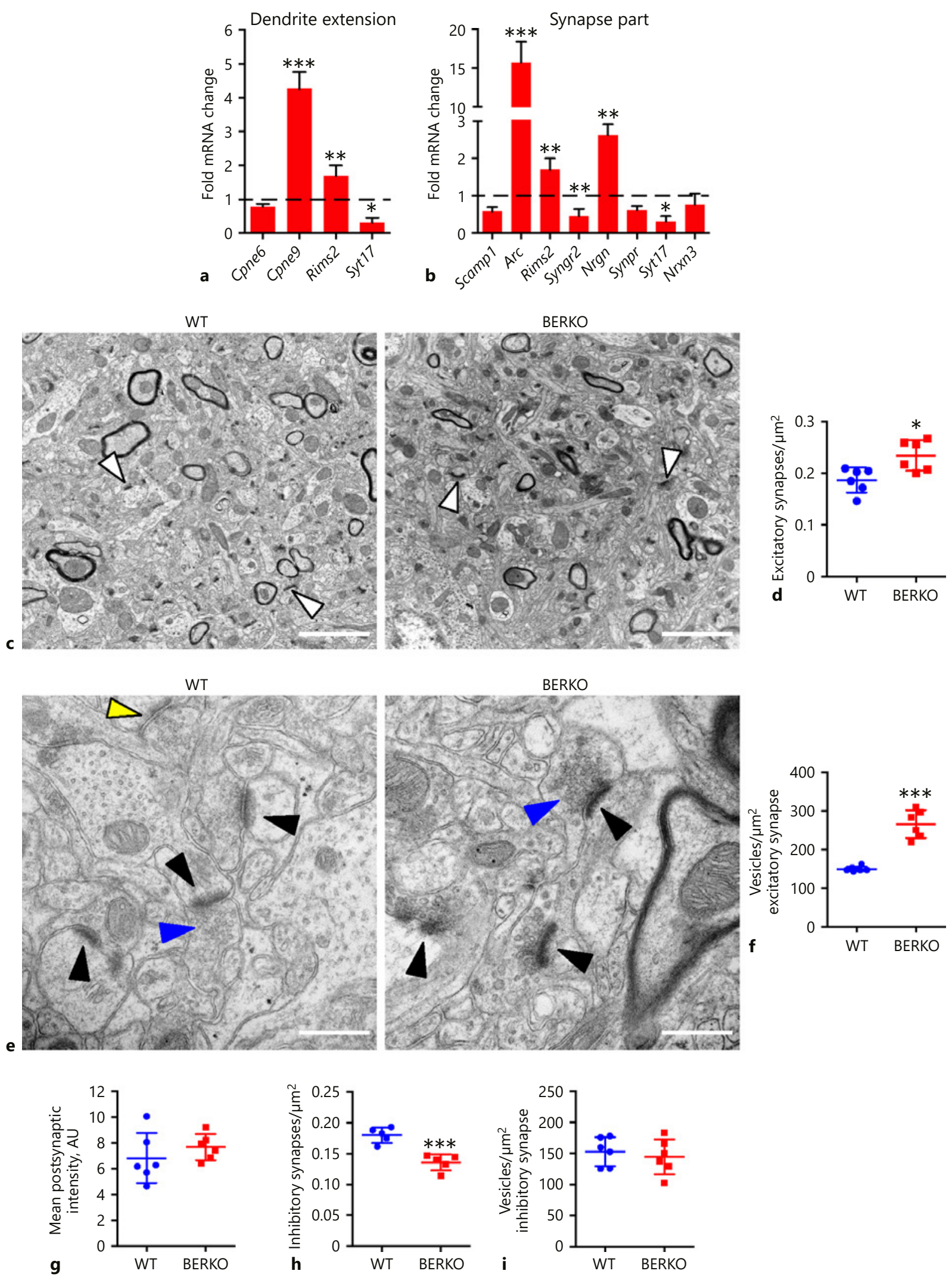
were not as strong as with the STRT RNA sequencing analysis. This could either imply that there is indeed a slight difference in gene expression between the left and right $\mathrm{M} 1$ cortices or that the needle puncture for the STRT RNA sequencing was not taken at the exact same spot between the mice and between left and right cortices.

Of note, ER $\beta$ was not a significantly differentially expressed gene in the RNA sequencing experiment, and RT-qPCR analysis showed that expression of ER $\beta$ is close to the detection limit in the M1 cortex (online suppl. Fig. 2A). Immunohistochemical analysis of the M1 cortex revealed that only few cells, both neuronal and nonneuronal (online suppl. Fig. 2B, C), expressed ER $\beta$, and that $\mathrm{ER} \beta$ was found to be sparsely distributed throughout the WT motor cortex and nearby cortical regions (judging from ER $\beta$ staining in coronal sections; online suppl. Fig. 3A, B).

Increased Accumulation of Neurotransmitter Vesicles in Excitatory Synapses of the BERKO M1 Cortex

We confirmed the differential regulation of all selected genes identified (except for Cpne6) in the STRT RNA sequencing data, supposedly involved in dendrite extension processes, by RT-qPCR: copine 9 (Cpn9), synaptic membrane exocytosis 2 protein (Rims2), and synaptotagmin 17 (Syt17) (Fig. 3a). These are involved in calcium-dependent membrane trafficking and exocytosis and thus also directly involved in synapse function. For the genes identified to be involved in the synapse component pathway, most were associated with neurotransmitter vesicle transport and release. As such, we confirmed by RT-qPCR that there was reduced expression of the presynaptic membrane trafficking proteins synaptogyrin 2 (Syngr2) and synaptotagmin 17 (Syt17) as well as increased expression of Rims 2 and postsynaptic proteins involved in signal transduction: activity-regulated cytoskeleton-associated protein $(A r c)$ and neurogranin (Nrgn) (Fig. 3b). Although the cell adhesion molecule neurexin 3 (Nrxn3) as well as the presynaptic proteins synaptoporin (Synpr) and secretory carrier membrane protein 1 (Scamp1) were significantly downregulated in the RNA sequencing data, we could not confirm this by RT-qPCR.

Since these results point to altered neurotransmitter vesicle trafficking and exocytosis, we used transmission electron microscopy (TEM) to analyze synapses in the BERKO M1 cortex. This analysis revealed an increased number of excitatory asymmetric synapses in the BERKO M1 cortex layers III-V as compared with WT M1 cortex (Fig. 3c, d). These excitatory synapses had increased numbers of neurotransmitter vesicles (Fig. 3e, f), which could reflect the altered expression of presynaptic proteins involved in neurotransmitter transport and vesicle release (Fig. 3a, b). However, although the postsynaptic signal transduction genes Arc and Nrgn are overexpressed in the BERKO M1 cortex, there was no significant increase in excitatory postsynaptic protein density (Fig. 3g). On the other hand, there was a decrease in the number of symmetric GABAergic synapses (Fig. 3h), but no change in inhibitory neurotransmitter vesicles (Fig. 3i). We could however not observe similar differences when analyzing the prefrontal cortex by TEM, a region not directly associated with motor control, except for a reduced number of inhibitory synapses in the BERKO prefrontal cortex (online suppl. Fig. 4A-E). This suggests that ER $\beta$ has spatially limited or distinct effects within the cortex. With regard to differences between the left and right M1 cortex, we could detect a slightly (nonsignificant) higher number of excitatory synapses in the right compared to left
Fig. 4. Increased excitatory synaptic transmission in the BERKO M1 cortex. a Representative traces of spontaneous excitatory postsynaptic currents from layers II-III pyramidal neurons of WT (blue) and BERKO (red) M1 cortex. b, c The amplitude (b) ( $t$ test WT vs. BERKO $t=2.522, \mathrm{df}=4, p=0.0652)$ and frequency $(\mathbf{c})(t$ test WT vs. BERKO $t=5.010, \mathrm{df}=4, p=0.0074$ ) of spontaneous excitatory postsynaptic current from WT and BERKO pyramidal neurons was measured (11 neurons from 3 WT M1 cortices and 11 neurons from 3 BERKO M1 cortices). Right graphs show cumulative probability distributions of amplitude and interevent interval. $\mathbf{d}$ Representative TEM images of mitochondria in excitatory presynapses of WT and BERKO M1 cortex. Mitochondria are highlighted with blue outline; arrowheads point out presynaptic mitochondria. Scale bars, $500 \mathrm{~nm}$. e, f Quantification of percentage of presynaptic mitochondria ( $t$ test WT vs. BERKO $t=2.578, \mathrm{df}=$
$6, p=0.0419)(\mathbf{e})$ and presynaptic mitochondria length $(t$ test WT vs. BERKO $t=0.4260, \mathrm{df}=6, p=0.6850$ ) (f) in WT and BERKO M1 cortex. g Representative high-contrast images of calretininpositive neurons in WT and BERKO right M1 cortex. Inset Calretinin immunofluorescence at low contrast. Yellow box: area of quantification, $1 \mathrm{~mm}^{2}$. Blue box: magnified area representing part of quantified cells. Scale bars, $100 \mu \mathrm{m}$. h Quantification of the number of calretinin-positive neurons ( 23 slides from $5 \mathrm{WT}$ and 5 BERKO mice) ( $t$ test WT vs. BERKO $t=4.586, \mathrm{df}=44, p<0.001$ ). $p$ values were obtained using Student's $t$ test. ${ }^{*} p<0.05$, ${ }^{* * *} p<$ 0.001 compared to WT. Data represent means \pm standard errors of the mean in $\mathbf{b}, \mathbf{c}, \mathbf{e}, \mathbf{f}$ and means \pm standard deviation in $\mathbf{h}(n=3$ in $\mathbf{b}$ and $\mathbf{c} ; n=4$ in $\mathbf{e}$ and $\mathbf{f} ; n=5$ in $\mathbf{h}$ ). BERKO, estrogen receptor beta knockout; M1 cortex, primary motor cortex; S, excitatory synapse; TEM, transmission electron microscopy; WT, wild-type.

(For figure see next page.)
Varshney et al. 


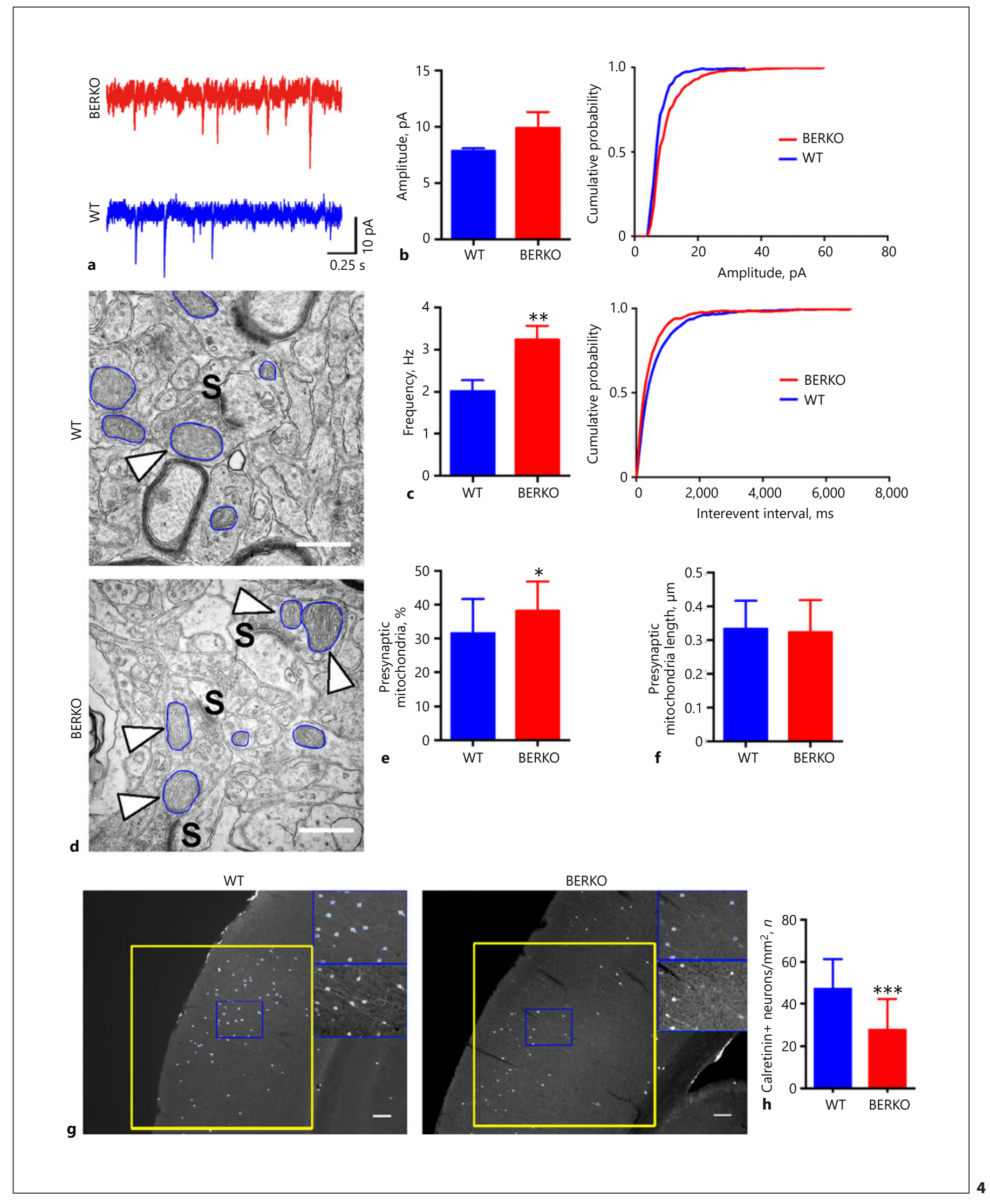

Loss of ER $\beta$ Is Associated with Motor

Neuroendocrinology 2021;111:27-44 Function Deficits DOI: $10.1159 / 000506162$ 
BERKO M1 cortex (online suppl. Fig. 4F). These excitatory synapses had also a significantly increased number of neurotransmitter vesicles in the right compared to the left BERKO M1 cortex (online suppl. Fig. 4G). However, there was no significant interaction between genotype and hemisphere in any measurement (online suppl. Fig. $4 \mathrm{~F}-\mathrm{J}$ ), suggesting that the observed differences in synapses between hemispheres are minor compared to the differences between genotypes.

\section{Increased Excitatory Transmission in the BERKO M1 Cortex}

To test whether the higher number of excitatory synapses and excitatory vesicles in the BERKO M1 cortex affected neuronal signal transduction, we measured spontaneous excitatory postsynaptic currents of pyramidal neurons in layers II-III. We detected an increase in both amplitude (Fig. 4a, b; nonsignificant) and frequency (Fig. 4a, c; significant) in BERKO pyramidal neurons, suggesting that accumulation of vesicles in the excitatory BERKO synapses is linked to higher excitatory synaptic activity. Neurotransmitter release is an energy-consuming event, reflected by abundant presynaptic mitochondria at the excitatory synapses. We detected a slight but significant increase in the number of excitatory synaptic mitochondria in the BERKO M1 cortex (Fig. 4d, e). These mitochondria looked healthy, with no difference in size compared to WT mitochondria (Fig. 4d, f). Since increased excitatory neurotransmission could be due to reduced inhibitory input, we analyzed the number of inhibitory calretinin-positive interneurons. Indeed, there was a significant reduction in the number of calretininpositive interneurons in BERKO compared to WT M1 cortex (Fig. 4g, h; online suppl. Fig. 5). Together, these data suggest increased excitatory neurotransmission in

Fig. 5. Differences in axonal myelination in BERKO M1 cortex. a RT-qPCR analysis of differently regulated genes involved in axonal myelination in BERKO compared to WT M1 cortex (dashed line). The data represent expression values from right M1 cortex (online suppl. Fig. 1C, D). b Mbp staining of WT and BERKO cortex. Scale bars, $200 \mu \mathrm{m}$. Blue squares represent magnified images depicted in the lower panel. c Quantification of Mbp staining in WT and BERKO M1 cortex layer III by mean gray intensity ( $t$ test WT vs. BERKO $t=3.922, \mathrm{df}=6, p=0.0078)$. d Representative images of myelinated axons in the WT and BERKO M1 cortex. Scale bars, $1 \mu \mathrm{m}$. Arrowheads show disruptions in myelin sheath compactization. e Quantification of average myelin g ratios in WT and BERKO M1 cortex ( $t$ test WT vs. BERKO $t=3.572, \mathrm{df}=8, p=$ 0.0073 ) and $g$ ratios as a function of axon diameter length. $f$ The the BERKO M1 cortex, which in turn could be ascribed to decreased GABAergic inhibition.

\section{Gross Morphological Myelination Changes in the BERKO M1 Cortex}

By using RT-qPCR analysis, we confirmed the data from RNA sequencing showing differential expression of key proteins involved in myelin compactization, stabilization, and maintenance, including proteolipid protein 1 $(P l p 1)$, myelin basic protein $1(M b p)$, claudin $11(C l d n 11)$, and $2^{\prime}, 3^{\prime}$-cyclic nucleotide phosphodiesterase (CNPase, Cnp) (but not contactin-associated protein 1, Cntnap1) (Fig. 5a). A qualitative analysis of Mbp staining indicated increased myelinated processes projecting to layers II and III of both the left and right M1 cortex (Fig. 5b, c). Quantification of Mbp staining intensities in layers II-III revealed significantly higher $\mathrm{Mbp}$ immunoreactivity in the BERKO M1 cortex (Fig. 3c, right panel; online suppl. Fig. 6A) (concomitant with increased Plp1 staining; online suppl. Fig. 6B). Qualitative analyses could not correlate this to any increased number of neurons in these layers or total number of cells judged by DAPI staining (online suppl. Fig. 6C). However, a more disordered layering could be detected in the BERKO motor cortex (online suppl. Fig. 6C) (similar to what was reported earlier [11]). No disordered layering was seen in the prefrontal cortex (online suppl. Fig. 6D), suggesting that the defect was spatially limited within the BERKO cortex.

\section{Thicker Myelin Sheaths in BERKO M1 Cortex}

In order to quantify any differences in myelin thickness and the integrity of the myelin sheaths, we analyzed layers II-V of WT and BERKO M1 cortex by TEM. Microstructural disruptions of myelin sheath compactization and significantly increased thickness in axon myelin-

scatter plot depicts $r^{2}$ values and slopes (WT [blue] $n=80$ from 5 mice; BERKO [red] $n=75$ from 5 mice). Linear regression analysis showed that there was no significant difference between the slopes $\left(F_{(1,151)}=0.6919, p=0.4068\right)$; however, there was a highly significant difference between the slope elevations $\left(F_{(1,152)}=30.538, p<\right.$ 0.001 ) where lower $g$ ratios in BERKO correlated with axons of smaller diameter. $p$ values were obtained using one-way ANOVA with Dunnett's correction for multiple comparisons (a) or Student's $t$ test $(\mathbf{c}, \mathbf{e}) .{ }^{*} p<0.05,{ }^{* *} p<0.01,{ }^{* * *} p<0.001$ compared to WT. Data represent means \pm standard deviations $(\mathbf{a}, \mathbf{c})$ or means \pm standard errors of the mean (e) $(n=5$ in a and e; $n=4$ in $\mathbf{c})$. AU, arbitrary units; BERKO, estrogen receptor beta knockout; M1 cortex, primary motor cortex; M2 cortex, secondary motor cortex; WT, wild-type.

(For figure see next page.)

38

Neuroendocrinology 2021;111:27-44 DOI: $10.1159 / 000506162$
Varshney et al. 
ation were more prominent in the BERKO compared to WT M1 cortex (Fig. 5d). The g ratio (ratio of inner to outer diameter of the myelin sheath) was significantly lower in BERKO M1 cortex (Fig. 5e), reflecting thicker myelination. In particular, thinner BERKO axons had significantly increased myelin thickness (lower g ratios) compared to similar-sized axons in the WT M1 cortex (Fig. 5f). We could not see the same effects in the prefrontal cortex (online suppl. Fig. 6E-H), and there was no significant interaction between genotype and left or right hemisphere in any measurement (online suppl. Fig. 6A, B, E).
Loss of ER $\beta$ Promotes Oligodendrogliogenesis but Impairs OL Functionality

Axonal myelination involves the differentiation of OL progenitor cells (OPCs) to mature OLs. It was previously reported that loss of ER $\beta$ in OPCs and OLs impacts on their remyelination capacity in models of multiple sclerosis [17] and that loss of ER $\beta$ in neural stem cell cultures leads to increased Olig2-positive OPCs and precocious oligodendrogliogenesis [29]. We analyzed the number of Olig2-positive OPCs in the BERKO M1 cortex and found an increase in OPC numbers, particularly in the deeper layers of the BERKO M1 cortex compared to the WT M1

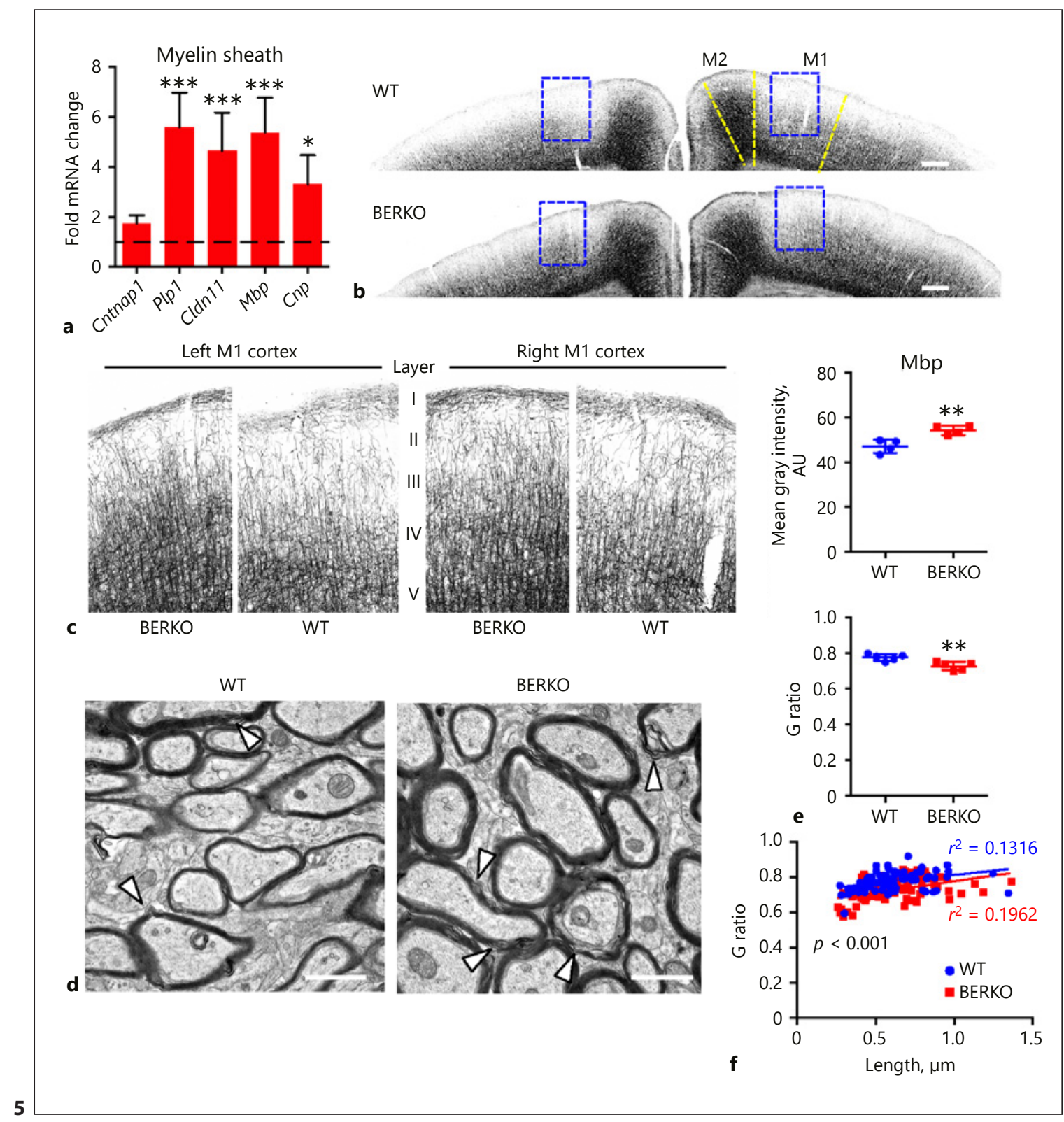


cortex (Fig. 6a, b; online suppl. Fig. 7A), and that many of these OPCs also expressed ER $\beta$ (Fig. 6c). Such an increase could reflect the increase in myelination observed in the BERKO M1 cortex (Fig. 5b-f). An important signaling factor that promotes activity-regulated myelination is BDNF. It was therefore surprising to find a decrease in BDNF levels in the BERKO cortex (Fig. 6d), indicating that increased excitatory synaptic activity is not responsible for the increase in myelination in the BERKO M1 cortex and that other ER $\beta$-regulated factors must be involved. In order to test the functionality of BERKO OLs, we differentiated WT and BERKO mESCs to the OL lineage. These cultures contain predominantly OLs and have a smaller fraction of astrocytes and neurons. Both OPCs and OLs express ER $\beta$, where the mature OLs have distinct process branching (online suppl. Fig. 7B, C). BERKO OLs had both shorter (Fig. 6e, f) and fewer (less branched) processes (Fig. 6e, g) compared to WT OLs. In addition, although the seeding density was the same, the BERKO cultures had increased numbers of OLs (Fig. 6e, h; online suppl. Fig. 7C), but did not proportionally produce more BDNF (Fig. 6i). These data suggest that loss of

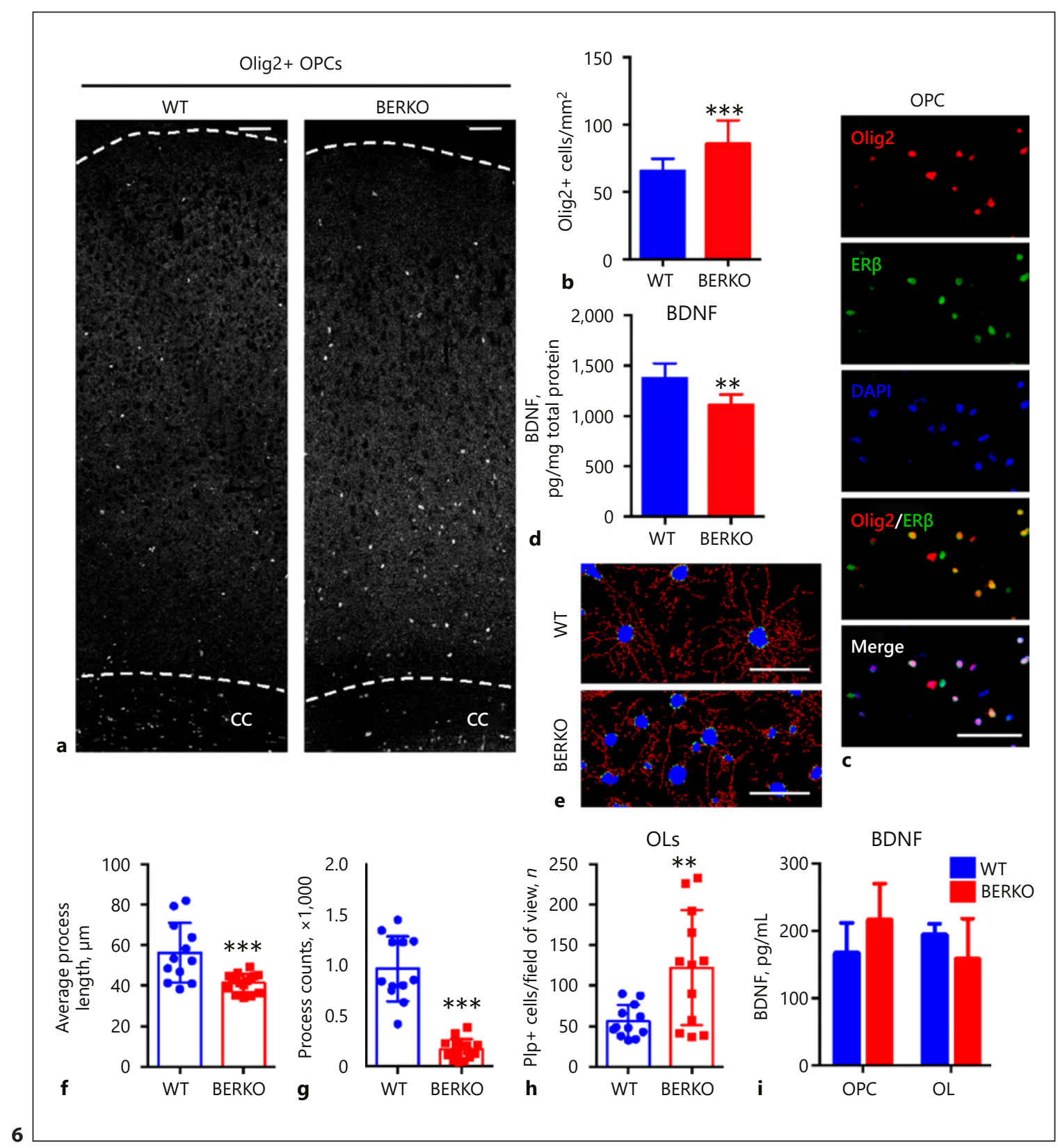

(For legend see next page.) 
$E R \beta$ results in increased number, but less functional OLs, which can impact on axonal myelination in the BERKO M1 cortex.

\section{Discussion and Conclusion}

In this study, we showed that ER $\beta$ is an important factor for proper neurotransmission and axonal myelination in the M1 cortex. Although we found ER $\beta$ throughout the adult mouse M1 cortex, the expression was not prominent and the transcript level was low. However, ER $\beta$ is highly expressed in the cerebral cortex during neurodevelopment $[5,13]$, which may suggest that the effects observed in this study could potentially be ascribed to neurodevelopmental deficiencies as a result of ER $\beta$ loss, or they could be due to ER $\beta$ loss in other brain areas projecting to the M1 cortex.

Several studies have shown that BERKO mice display increased anxiety and context-dependent aggression [7, $8,32]$, which is linked to altered serotonergic signaling mainly in the basolateral amygdala $[32,33]$ and the dorsal raphe $[34,35]$ as well as to changes in the ratio of ERa to ER $\beta$ signaling in the preoptic area [9]. Although others have reported that BERKO mice spend less time in the center of the open-field arena as a consequence of the anxiolytic effects of $\operatorname{ER} \beta[8,32,33]$, we could not observe this in our study. However, we could confirm increased anxiety of the BERKO mice in the elevated plus maze. In addition, while previous studies have shown no difference [33] or a slight increase $[8,32]$ in motor activity in the open-field test, we found a significantly higher locomotor activity of BERKO mice. The differences between open-field tests may potentially be due to different

Fig. 6. Loss of ER $\beta$ results in increased OL progenitor cells and deficits in process branching by mature OLs. a Representative images of Olig2-positive cells in WT and BERKO M1 cortex (dashed line represents the border of the cortex. Scale bars, $50 \mu \mathrm{m}$. b Quantification of Olig2-positive cells in WT and BERKO M1 cortex ( $n=14$ fields of view from three WT M1 cortices, and $n=11$ fields of view from three BERKO M1 cortices) ( $t$ test WT vs. BERKO $t=$ $3.768, \mathrm{df}=23, p<0.001)$. c Olig2 and $\mathrm{ER} \beta$ expression in deep layer OPCs of the WT M1 cortex (blue: DAPI-stained cell nuclei). Scale bar, $50 \mu \mathrm{m}$. d BDNF levels in WT and BERKO cortical extracts (WT $n=5$, BERKO $n=6)(t$ test WT vs. BERKO $t=3.370$, $\mathrm{df}=9, p=0.0083$ ). e Representative skeletonized images of WT and BERKO OL cultures (blue: DAPI-stained cell nuclei; red: Plppositive processes; green: process attachment points). Scale bars, $100 \mu \mathrm{m}$. f-h Quantification of process length (f) ( $t$ test WT vs. BERKO $t=3.821, \mathrm{df}=26, p<0.001)$, process counts $(\mathbf{g})(t$ test WT

Loss of ER $\beta$ Is Associated with Motor Function Deficits
BERKO mouse lines, but it may also be due to different open-field arena sizes and time of data acquisition during the experiment. For instance, our study used the more appropriate $50-\mathrm{cm}^{2}$ open-field arena to measure locomotor activity in mice [36] than Krezel et al. [32] (who used a very large open-field arena, which could impact on such behavior), and we measured distances traveled as a function of time. In addition, we saw a significant increase in rearing activity by BERKO mice, which was not observed in the study by Krezel et al. Increased rearing (as means of gathering contextual information) correlates with increased locomotion (as means of free exploration) in a novel environment [37] and can also be regarded as an index of nonselective attention during habituation [38, 39]. The BERKO mice showed increased rearing frequency, especially $10-15 \mathrm{~min}$ into the test after the initial novelty phase, suggesting that nonselective attention may be compromised in BERKO mice, similar to what is seen in rodent models of attention deficit hyperactivity disorder $[38,40]$. Our results also point out that care must be taken in interpreting BERKO mouse behavior data, since behavior test setups and probably also mouse strain backgrounds may impact on the results.

Although many circuits and brain areas may be involved in the hyperactivity of the BERKO mice, we chose to focus on the M1 cortex, which is important for planning and execution of movements. Pathway analysis of RNA sequencing data from the left and right M1 cortex revealed that mainly two cellular components were affected: the synapse and the myelin sheath.

Electron microscopical and electrophysiological analyses in this study showed an increased number of excitatory synapses and excitatory neurotransmitter vesicles in the BERKO adult M1 cortex. Concurrently, a reduced

vs. BERKO $t=8.848, \mathrm{df}=24, p<0.001)$, and number of Plp-positive OLs (h) ( $t$ test WT vs. BERKO $t=3.097, \mathrm{df}=22, p=0.0053$ ) per field of view (12 fields of view from three WT cultures and 12-16 fields of view from three BERKO cultures). i BDNF levels in growth medium from WT and BERKO OPC and OL cultures $(n=$ 3 ) (two-way ANOVA of main effect of genotype $F_{(1,8)}=0.0560$, $p=0.8188$; culture type $F_{(1,8)}=0.3127, p=0.5913$; and interaction between genotype and culture type $\left.F_{(1,8)}=2.352, p=0.1637\right)$. $p$ values were obtained using Student's $t$ tests $(\mathbf{b}, \mathbf{d}, \mathbf{f}-\mathbf{h})$ or two-way ANOVA with Bonferroni's correction for multiple comparisons (i). ${ }^{* *} p<0.01,{ }^{* * *} p<0.001$ compared to WT. Data represent means \pm standard deviations. BDNF, brain-derived neurotrophic factor; BERKO, estrogen receptor beta knockout; CC, corpus callosum; ER $\beta$, estrogen receptor beta; M1 cortex, primary motor cortex; OL, oligodendrocyte; OPC, oligodendrocyte precursor cell; WT, wild-type. 
number of inhibitory calretinin-positive interneurons was found, which is in line with previous results demonstrating that $E R \beta$ is expressed in subsets of GABAergic interneurons $[16,41,42]$ and that loss of $\operatorname{ER} \beta$ results in fewer calretinin-positive interneurons, at least in the developing mouse brain [16]. This is likely in turn a consequence of deficits in cortical layering and neuronal migration during embryonic development observed in BERKO mice [14], and our data show that the deficits persist into adulthood. Interestingly, these effects were not observed in the prefrontal cortex, suggesting that ER $\beta$ has spatially different functions within the cortex, and not necessarily because the prefrontal cortex is the last part of the brain to develop. In addition, our data indicate that there may be differences in ER $\beta$ function between the left and right M1 cortex. STRT RNA sequencing analysis revealed that few genes were similarly regulated as a result of ER $\beta$ loss in the left compared to the right M1 cortex. It is important to keep in mind that STRT RNA sequencing requires very little starting material and is very sensitive to slight differences in needle puncture location or depth. The presence of such technical variation in tissue sampling is supported by RT-qPCR analysis, which requires larger biopsies and where we could not observe any major differences between left and right BERKO M1 cortices. Nor did our other functional studies detect such differences, with the exception of a slightly but significantly higher number of excitatory neurotransmitter vesicles in the right compared to the left BERKO M1 cortex (online suppl. Fig. 4G) and higher expression of the postsynaptic activity regulated protein $A r c$ in the right BERKO M1 cortex (online suppl. Fig. 1D). In addition, there was an overall trend that the right BERKO M1 cortex had in general more pronounced effects of ER $\beta$ loss than the left M1 cortex. However, statistical analyses showed that there was no overall interaction between genotype and hemisphere, suggesting that any difference between the hemispheres is minor to genotype differences.

One of the most striking effects of BERKO seen in this study was on axonal myelination. The myelinated fibers not only protruded deeper into layers II-III, but the thickness of the myelin sheaths was also increased, particularly around small-diameter axons. The effect was at least not directly BDNF-mediated through increased neuronal activity since we saw decreased instead of increased cortical BDNF levels. ER $\beta$ is expressed in neurons as well as in both OPCs and mature OLs and can contribute to BDNF expression [43]. However, as mentioned above, ER $\beta$ is not a major transcript in the adult M1 cortex, and the effects observed in our study are likely developmental or due to ER $\beta$ loss in other brain areas projecting to the motor cortex. In vitro cultures of WT and BERKO OPCs and OLs revealed that BERKO OLs may be less functional because both their process lengths and process counts were greatly reduced compared to those of WT OLs. Furthermore, as in our previous study [29], we found an increase in oligodendrogliogenesis in these co-cultures, suggesting that ER $\beta$ controls OPC differentiation and hence OL function. Again, this effect appears to be not directly dependent on BDNF signaling, since we did not see any difference in BDNF levels between WT and BERKO oligodendroglial cultures. ER $\beta$ has previously been reported to be an important factor in maintaining Notch/Hes signaling in various differentiating cell types, including neural progenitors $[29,44,45]$, and it is likely that loss of ER $\beta$ abrogates this signaling, resulting in increased oligodendrogliogenesis (as described in [29]) that in turn may feedback to decrease neuronal BDNF expression in the cortex. The molecular mechanisms underlying ER $\beta$ 's role in OL differentiation and function need further investigation and may have potential clinical implications in demyelinating diseases.

Our results add to the growing evidence supporting the importance of sex hormone signaling for normal development and functioning of the brain. Indeed, aberrant sex hormone signaling at sensitive developmental periods is linked to adverse neurological outcomes later in life, often with clear sex differences in risk, progression, and severity $[46,47]$. In this study we used adult male mice, but in light of sex differences observed in attention disorders [48, 49] and the fact that females have higher circulating E2 levels, it would be very interesting to perform the same experiments in female mice. However, it is not certain that females would show different responses despite higher circulating E2 levels, since testosterone is readily aromatized to E2 in the rodent male brain [50]. Furthermore, we and others have shown that ER $\beta$ signals to a great extent ligand-independently $[29,47,51]$. Nevertheless, targeting neuroactive steroid signaling may pose interesting new therapeutic approaches in neurological disorders [52], and our future plans include the use of female mice and treatments with $E R \beta$-selective ligands.

In conclusion, our data show that loss of $\operatorname{ER} \beta$ in mice results in locomotor deficits as well as in behavior that may be indicative of compromised nonselective attention, which are similar to, but less profound than, behavioral phenotypes found in attention deficit hyperactivity disorder mouse models. These effects may at least partly be ascribed to abnormal synaptic and myelination processes in the M1 cortex, where we observed increased excitatory synapse activity, decreased inhibitory synapses, and de-
Varshney et al. 
creased calretinin-positive interneurons as well as increased myelination and an increased number of immature Olig2-positive OLs. The effects are likely to be neurodevelopmental, where ER $\beta$ loss is known to deregulate Notch/Hes [29] and BDNF signaling [43], pointing out the importance of proper $\mathrm{ER} \beta$ function during corticogenesis.

\section{Acknowledgements}

The authors would like to thank the Karolinska Institutet Mouse Models, the Electron Microscopy Unit at Karolinska Institutet, the Murine Stem Cell Unit at Karolinska Institutet, and the Live Cell Imaging Facility at Karolinska Institutet. The expertise and equipment at these facilities made substantial contributions to the feasibility of the study.

\section{Statement of Ethics}

All animal experiments were carried out according to Swedish guidelines governing animal experimentation and were approved by the local veterinary and agricultural authorities (approval numbers: S48-14 and S18-14), the Linköping local ethics committee for Karolinska Institute South Campus (Linköping, Sweden), as well as the Institutional Animal Research Ethics Committee of Third Military Medical University (Chongqing, China).

\section{Disclosure Statement}

The authors have no conflicts of interest to declare.

\section{Funding Sources}

This study was supported by the Center for Innovative Medicine, Swedish Research Council (\#2017-01094 and \#2016-02860), the NovoNordisk foundation (\#NNF16OC0020704), the Emil and Wera Cornell Foundation, the Swedish Brain Foundation (Hjärnfonden, to J. Kere), the Knut and Alice Wallenberg foundation (\#2015-0096, to V. Töhönen), and the Karolinska Institutet. The support included salaries, animal costs, and running costs of relevance to the study.

\section{Author Contributions}

M.K. Varshney, T. Liu, X. Li, V. Töhönen, X. Fan, W.-F. Wu, and J. Inzunza performed the experiments and analyzed the data. N.Y.-L. Yu, K. Krjutškov, and S. Katayama performed the STRT RNA sequencing analysis. J. Kere, J.-Å. Gustafsson, and I. Nalvarte conceived the study. All authors discussed and wrote the paper. I. Nalvarte led the study.

\section{References}

1 Kelly MJ, Qiu J. Estrogen signaling in hypothalamic circuits controlling reproduction. Brain Res. 2010 Dec;1364:44-52.

2 Brann DW, Dhandapani K, Wakade C, Mahesh VB, Khan MM. Neurotrophic and neuroprotective actions of estrogen: basic mechanisms and clinical implications. Steroids. 2007 May;72(5):381-405.

3 Simpkins JW, Singh M, Brock C, Etgen AM. Neuroprotection and estrogen receptors. Neuroendocrinology. 2012;96(2):119-30.

4 Liu F, Day M, Muñiz LC, Bitran D, Arias R, Revilla-Sanchez R, et al. Activation of estrogen receptor-beta regulates hippocampal synaptic plasticity and improves memory. Nat Neurosci. 2008 Mar;11(3):334-43.

5 Bondesson M, Hao R, Lin CY, Williams C, Gustafsson JA. Estrogen receptor signaling during vertebrate development. Biochim Biophys Acta. 2015 Feb;1849(2):142-51.

6 González M, Cabrera-Socorro A, Pérez-García CG, Fraser JD, López FJ, Alonso R, et al. Distribution patterns of estrogen receptor alpha and beta in the human cortex and hippocampus during development and adulthood. J Comp Neurol. 2007 Aug;503(6):790802.

7 Imwalle DB, Gustafsson JA, Rissman EF. Lack of functional estrogen receptor beta influenc- es anxiety behavior and serotonin content in female mice. Physiol Behav. 2005 Jan;84(1): 157-63.

8 Ogawa S, Chan J, Chester AE, Gustafsson JA, Korach KS, Pfaff DW. Survival of reproductive behaviors in estrogen receptor beta genedeficient (betaERKO) male and female mice. Proc Natl Acad Sci USA. 1999 Oct;96(22): 12887-92.

9 Nakata M, Sano K, Musatov S, Yamaguchi N, Sakamoto T, Ogawa S. Effects of Prepubertal or Adult Site-Specific Knockdown of Estrogen Receptor $\beta$ in the Medial Preoptic Area and Medial Amygdala on Social Behaviors in Male Mice. eNeuro. 2016 Mar;3(2):ENEURO.0155-15.2016.

10 Khalaj AJ, Hasselmann J, Augello C, Moore S, Tiwari-Woodruff SK. Nudging oligodendrocyte intrinsic signaling to remyelinate and repair: estrogen receptor ligand effects. J Steroid Biochem Mol Biol. 2016 Jun;160:43-52.

11 Wang L, Andersson S, Warner M, Gustafsson JA. Morphological abnormalities in the brains of estrogen receptor beta knockout mice. Proc Natl Acad Sci USA. 2001 Feb;98(5):2792-6.

12 Walf AA, Koonce CJ, Frye CA. Adult female wildtype, but not oestrogen receptor beta knockout, mice have decreased depressionlike behaviour during pro-oestrus and follow- ing administration of oestradiol or diarylpropionitrile. J Psychopharmacol. 2009 Jun; 23(4):442-50.

13 Fan $\mathrm{X}, \mathrm{Xu} \mathrm{H}$, Warner M, Gustafsson JA ERbeta in CNS: new roles in development and function. Prog Brain Res. 2010;181:233-50.

14 Wang L, Andersson S, Warner M, Gustafsson JA. Estrogen receptor (ER)beta knockout mice reveal a role for ERbeta in migration of cortical neurons in the developing brain. Proc Natl Acad Sci USA. 2003 Jan;100(2): 703-8.

15 Xu P, Guo L, Tang X, Xu H, Fan X. ER $\beta$ may contribute to the maintaining of radial glia cells polarity through cadherins during corticogenesis. Med Hypotheses. 2011 Dec;77(6): 974-6.

16 Fan X, Warner M, Gustafsson JA. Estrogen receptor beta expression in the embryonic brain regulates development of calretinin-immunoreactive GABAergic interneurons. Proc Natl Acad Sci USA. 2006 Dec;103(51):1933843.

17 Khalaj AJ, Yoon J, Nakai J, Winchester Z, Moore SM, Yoo T, et al. Estrogen receptor (ER) $\beta$ expression in oligodendrocytes is required for attenuation of clinical disease by an ER $\beta$ ligand. Proc Natl Acad Sci USA. 2013 Nov;110(47):19125-30. 
18 Krege JH, Hodgin JB, Couse JF, Enmark E, Warner M, Mahler JF, et al. Generation and reproductive phenotypes of mice lacking estrogen receptor beta. Proc Natl Acad Sci USA. 1998 Dec;95(26):15677-82.

19 Islam S, Zeisel A, Joost S, La Manno G, Zajac $\mathrm{P}$, Kasper M, et al. Quantitative single-cell RNA-seq with unique molecular identifiers. Nat Methods. 2014 Feb;11(2):163-6.

20 Krjutškov K, Katayama S, Saare M, Vera-Rodriguez M, Lubenets D, Samuel K, et al. Single-cell transcriptome analysis of endometrial tissue. Hum Reprod. 2016 Apr;31(4):84453.

21 Kivioja T, Vähärautio A, Karlsson K, Bonke $M$, Enge M, Linnarsson S, et al. Counting absolute numbers of molecules using unique molecular identifiers. Nat Methods. 2011 Nov;9(1):72-4.

22 Pruitt KD, Tatusova T, Brown GR, Maglott DR. NCBI Reference Sequences (RefSeq): current status, new features and genome annotation policy. Nucleic Acids Res. 2012 Jan; 40(Database issue):D130-5.

23 Langmead B, Trapnell C, Pop M, Salzberg SL. Ultrafast and memory-efficient alignment of short DNA sequences to the human genome. Genome Biol. 2009;10(3):R25.

24 Kim D, Pertea G, Trapnell C, Pimentel H, Kelley R, Salzberg SL. TopHat2: accurate alignment of transcriptomes in the presence of insertions, deletions and gene fusions. Genome Biol. 2013 Apr;14(4):R36.

25 Katayama S, Töhönen V, Linnarsson S, Kere J. SAMstrt: statistical test for differential expression in single-cell transcriptome with spike-in normalization. Bioinformatics. 2013 Nov;29(22):2943-5.

26 Li J, Tibshirani R. Finding consistent patterns: a nonparametric approach for identifying differential expression in RNA-Seq data. Stat Methods Med Res. 2013 Oct;22(5):519-36.

27 Storey JD, Tibshirani R. Statistical significance for genomewide studies. Proc Natl Acad Sci USA. 2003 Aug;100(16):9440-5.

28 Tan XJ, Dai YB, Wu WF, Kim HJ, Barros RP, Richardson TI, et al. Reduction of dendritic spines and elevation of GABAergic signaling in the brains of mice treated with an estrogen receptor $\beta$ ligand. Proc Natl Acad Sci USA. 2012 Jan;109(5):1708-12.

29 Varshney MK, Inzunza J, Lupu D, Ganapathy V, Antonson P, Rüegg J, et al. Role of estrogen receptor beta in neural differentiation of mouse embryonic stem cells. Proc Natl Acad Sci USA. 2017 Nov;114(48):E10428-37.

30 Mehra RD, Sharma K, Nyakas C, Vij U. Estrogen receptor alpha and beta immunoreactive neurons in normal adult and aged female rat hippocampus: a qualitative and quantitative study. Brain Res. 2005 Sep;1056(1):22-35.

31 Ho SY, Chao CY, Huang HL, Chiu TW, Charoenkwan P, Hwang E. NeurphologyJ: an automatic neuronal morphology quantification method and its application in pharmacological discovery. BMC Bioinformatics. 2011 Jun; 12(1):230.

32 Krezel W, Dupont S, Krust A, Chambon P, Chapman PF. Increased anxiety and synaptic plasticity in estrogen receptor beta-deficient mice. Proc Natl Acad Sci USA. 2001 Oct; 98(21):12278-82.

33 Oyola MG, Portillo W, Reyna A, Foradori CD, Kudwa A, Hinds L, et al. Anxiolytic effects and neuroanatomical targets of estrogen receptor- $\beta(E R \beta)$ activation by a selective ER $\beta$ agonist in female mice. Endocrinology. 2012 Feb;153(2):837-46.

34 Suzuki H, Barros RP, Sugiyama N, Krishnan V, Yaden BC, Kim HJ, et al. Involvement of estrogen receptor $\beta$ in maintenance of serotonergic neurons of the dorsal raphe. Mol Psychiatry. 2013 Jun;18(6):674-80.

35 Clark JA, Alves S, Gundlah C, Rocha B, Birzin ET, Cai SJ, et al. Selective estrogen receptorbeta (SERM-beta) compounds modulate raphe nuclei tryptophan hydroxylase-1 (TPH-1) mRNA expression and cause antidepressantlike effects in the forced swim test. Neuropharmacology. 2012 Nov;63(6):1051-63.

36 Seibenhener ML, Wooten MC. Use of the Open Field Maze to measure locomotor and anxiety-like behavior in mice. J Vis Exp. 2015 Feb;96:e52434.

37 Lever C, Burton S, O'Keefe J. Rearing on hind legs, environmental novelty, and the hippocampal formation. Rev Neurosci. 2006;17(12):111-33.

38 Aspide R, Fresiello A, de Filippis G, Gironi Carnevale UA, Sadile AG. Non-selective attention in a rat model of hyperactivity and attention deficit: subchronic methylphenydate and nitric oxide synthesis inhibitor treatment. Neurosci Biobehav Rev. 2000 Jan;24(1):5971.

39 Aspide R, Gironi Carnevale UA, Sergeant JA, Sadile AG. Non-selective attention and nitric oxide in putative animal models of AttentionDeficit Hyperactivity Disorder. Behav Brain Res. 1998 Sep;95(1):123-33.

40 Qian Y, Lei G, Castellanos FX, Forssberg H, Heijtz RD. Deficits in fine motor skills in a genetic animal model of ADHD. Behav Brain Funct. 2010 Sep;6(1):51.

41 Blurton-Jones M, Tuszynski MH. Estrogen receptor-beta colocalizes extensively with parvalbumin-labeled inhibitory neurons in the cortex, amygdala, basal forebrain, and hippocampal formation of intact and ovariectomized adult rats. J Comp Neurol. 2002 Oct; 452(3):276-87.

42 Blurton-Jones M, Tuszynski MH. Estradiolinduced modulation of estrogen receptor-beta and GABA within the adult neocortex: a potential transsynaptic mechanism for estrogen modulation of BDNF. J Comp Neurol. 2006 Dec;499(4):603-12.

43 Chhibber A, Woody SK, Karim Rumi MA, Soares MJ, Zhao L. Estrogen receptor $\beta$ deficiency impairs BDNF-5-HT2A signaling in the hippocampus of female brain: A possible mechanism for menopausal depression. Psychoneuroendocrinology. 2017 Aug;82:10716.

44 Brooks YS, Ostano P, Jo SH, Dai J, Getsios S, Dziunycz $\mathrm{P}$, et al. Multifactorial ER $\beta$ and NOTCH1 control of squamous differentiation and cancer. J Clin Invest. 2014 May; 124(5):2260-76.

45 Fortini F, Vieceli Dalla Sega F, Caliceti C, Aquila G, Pannella M, Pannuti A, et al. Estrogen receptor $\beta$-dependent Notch1 activation protects vascular endothelium against tumor necrosis factor a (TNFa)-induced apoptosis. J Biol Chem. 2017 Nov;292(44):18178-91.

46 Gillies GE, McArthur S. Estrogen actions in the brain and the basis for differential action in men and women: a case for sex-specific medicines. Pharmacol Rev. 2010 Jun;62(2): 155-98.

47 Varshney M, Nalvarte I. Genes, Gender, Environment, and Novel Functions of Estrogen Receptor Beta in the Susceptibility to Neurodevelopmental Disorders. Brain Sci. 2017 Feb;7(3):E24

48 Arnett AB, Pennington BF, Willcutt EG, DeFries JC, Olson RK. Sex differences in ADHD symptom severity. J Child Psychol Psychiatry. 2015 Jun;56(6):632-9.

49 Rucklidge JJ. Gender differences in attentiondeficit/hyperactivity disorder. Psychiatr Clin North Am. 2010 Jun;33(2):357-73.

50 Shay DA, Vieira-Potter VJ, Rosenfeld CS. Sexually Dimorphic Effects of Aromatase on Neurobehavioral Responses. Front Mol Neurosci. 2018 Oct; $11: 374$

51 Vivar OI, Zhao X, Saunier EF, Griffin C, Mayba OS, Tagliaferri M, et al. Estrogen receptor beta binds to and regulates three distinct classes of target genes. J Biol Chem. 2010 Jul; 285(29):22059-66.

52 Porcu P, Barron AM, Frye CA, Walf AA, Yang SY, He XY, et al. Neurosteroidogenesis Today: Novel Targets for Neuroactive Steroid Synthesis and Action and Their Relevance for Translational Research. J Neuroendocrinol. 2016 Feb;28(2):12351. 